\title{
التأصيل الإسلامي والتربوي لنظرية (Z) اليابانية
}

أشواق عبدالرحمن الحقباني

باحثة دكتوراه في الإدارة التربوية

as0878@gmail.com
خلود إسحاق بخاري

باحثة دكتوراه في الإدارة التربوية

mslavendar333@gmail.com

قبول البحث: 2020/9/2 


\title{
التأصيل الإسلامي والتربوي لنظرية (Z) اليابانية
}

\author{
خلود إسحاق بخاري \\ باحثة دكتوراه في الإدارة التربوية \\ mslavendar333@gmail.com \\ أشواق عبدالرحمن الحقباني \\ باحثة دكتوراه في الإدارة التربوية \\ as0878@gmail.com
}

DOI: https://doi.org/10.31559/EPS2021.9.2.17 2020/9/2 2020/7/28 مراجعة البحث: 2020/8/11 قبول البحث البحث: 2017

\begin{abstract}
هدفت الدراسة إلى التعرف على خلفية ومبادئ وخصائص نظرية Z في الإدارة اليابانية، كما هدفت إلى بيان التأصيل الإسلامي لمبادئ

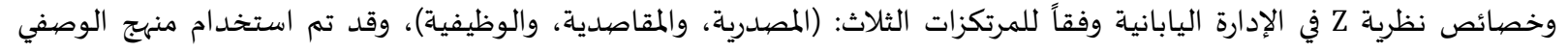

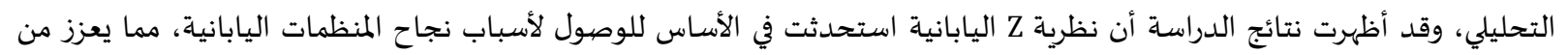

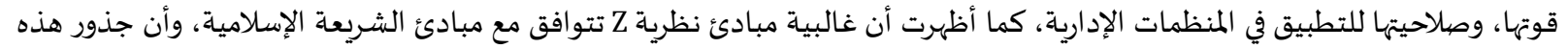

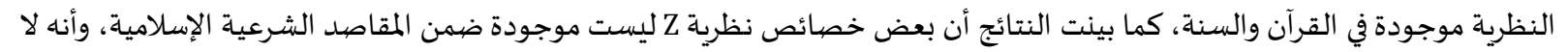
توجد موانع عقدية من تطبيق نظرية Z في المنظمات الإدارية الإسلامية. الكلمات المفتاحية: نظرية Z؛ الإدارة اليابانية؛ التأصيل الإسلامي؛ الإدارة الإسلامية؛ الإدارة التربوية.
\end{abstract}

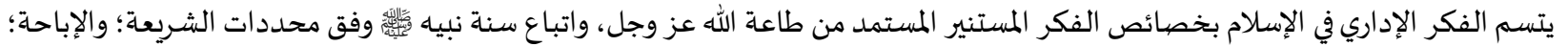

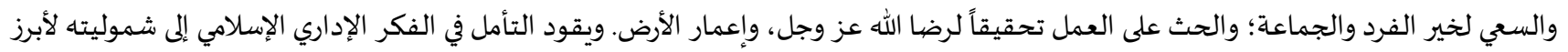

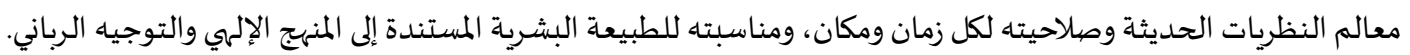

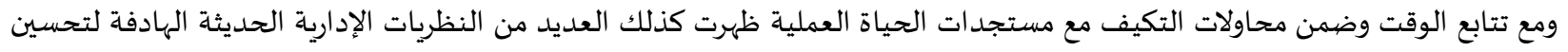

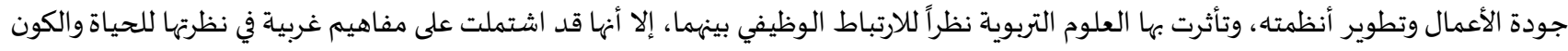

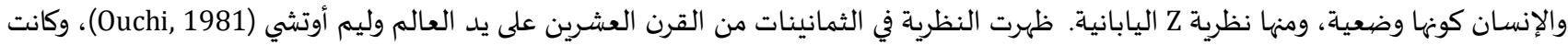

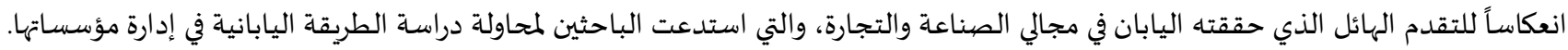

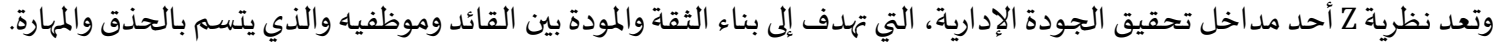

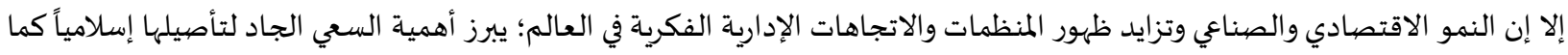

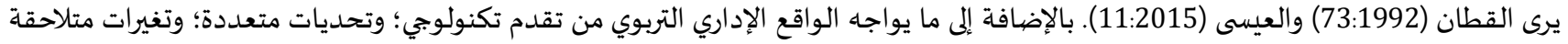

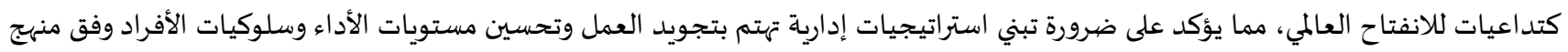


فبرزت الحاجة لتكوين مدرسة إدارية إسلامية تنطلق من الشريعة الإسلامية لبناء نظريات إدارية تربوية ترجع في أصول تكوينها للقرآن الكريم

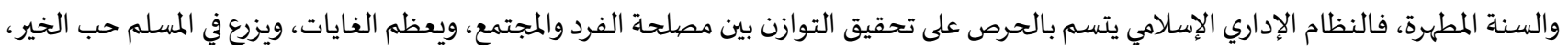
والحرص على نفع الإسلام والمسلمين، بل والبشرية جمعاء.

مشكلة الدراسـة:

أظهرت الدراسات في ميدان الإدارة التربوية نجاحاً للنموذج الإسلامي في الإدارة، والذي تميز بمرونته ومناسبته لمختلف العصهور والظروف، فالفكر

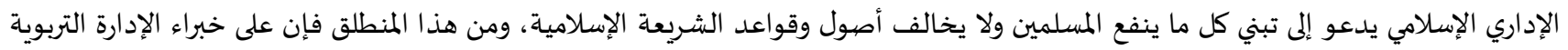

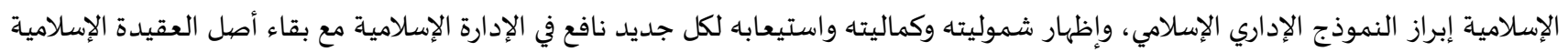

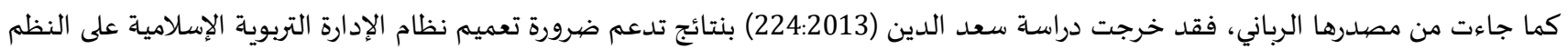

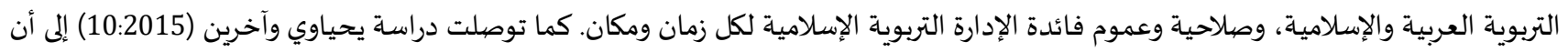

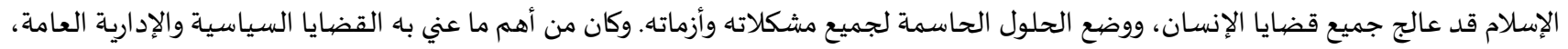

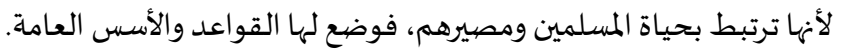

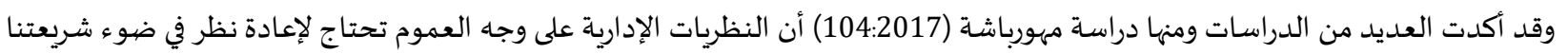
الإسلامية، والوقوف على الإطار الفلسفي، والتعرف على طبيعة العلاقة المعرفية التي تربط الأسس الفلسفية للحداثة الغربية بالنظريات التربوية. كما أظهرت دراسة عامر (245:2012) أن هناك توافقاً بين قيم أخلاقيات الإدارة اليابانية التي تتمثل في نظرية Z مع مبادئ وتعاليم الشريعة الإسلامية،

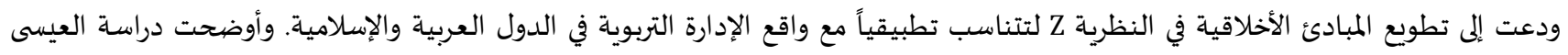

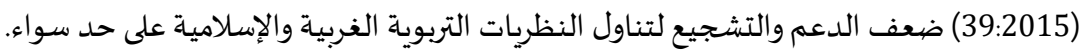

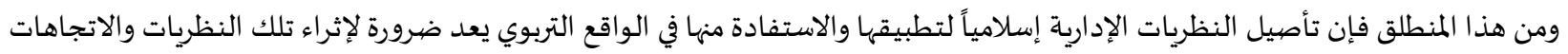

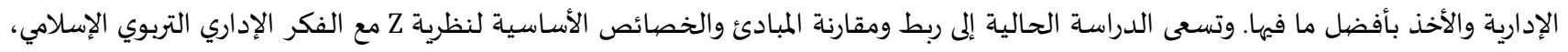

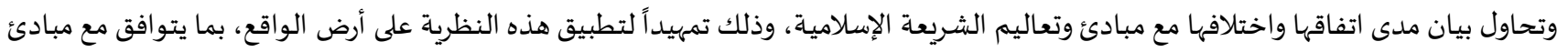

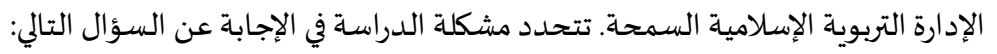

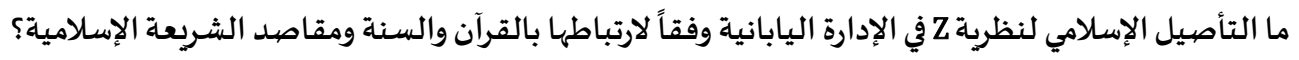
ويتفرع منه الأسئلة الفرعياة التالية:

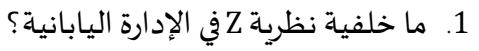

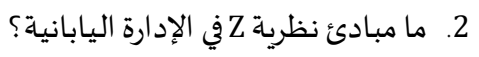
3. 4.

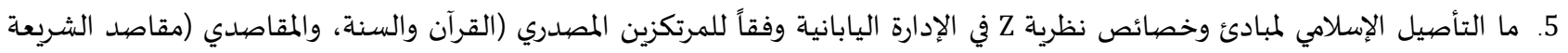

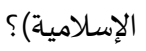

6. ما التأصيل الإسلامي لمبادئ وخصائص نظرية Z في الإدارة اليابانية بناءً على المرتكز الوظيفي بالإدارة التربوية؟

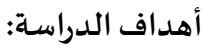
1. التعرف على خلفية نظرية Z في الإدارة اليابانية. 2.

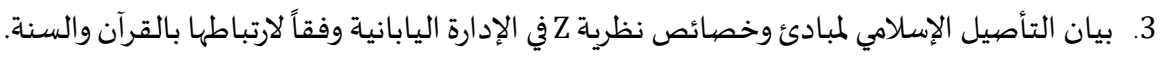

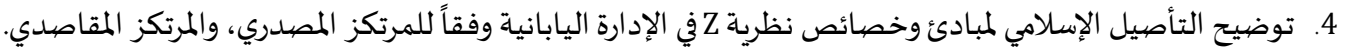

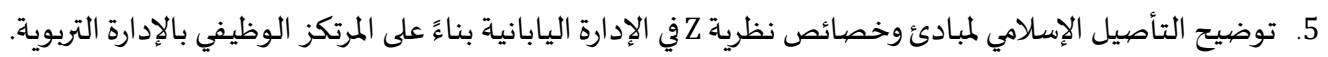

أهمية الدراسـة:

تتمثل أهمية الدراسة في النقاط التالية: 1. تسعى الدراسة الحالية لتوفير الأصل الإسلامي في نظرية Z في الإدارة اليابانية والتأكيد على مميزات وخصائص الإدارة الإسلامية ومنهجها في الحياة والعمل وقدرتها على البقاء والريادة. 
2. محاولة علمية قد تضيف إلى الأطر النظرية والتجارب في مجال إدارة الجودة الشاملة باعتبار نظرية Z في الإدارة اليابانية أحد أشكالها من حيث

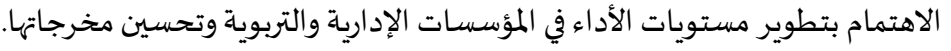

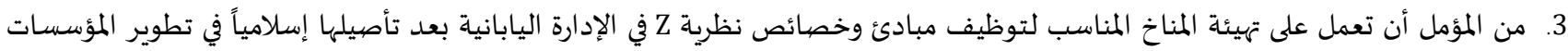

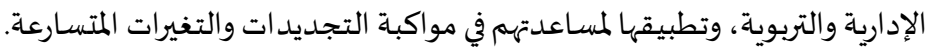

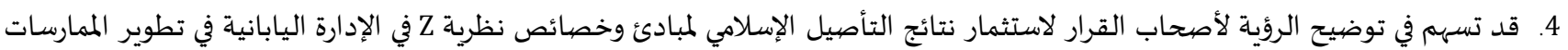
الداعمة لتطوير الأداء من خلال نتائجها وتوصياتها. تمنهج الدراسة:

خلفية نظرية Z في الإدارة اليابانية: تعرف حكيم (530:2010) نظرية Z بأهها نموذج إداري ياباني يجمع مفاهيم وأنماط مختلفة، وضعها العالم أوتشي، أحد أساتذة إدارة الأعمال في

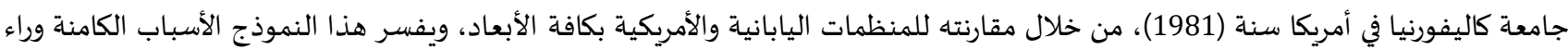
نجاح المنظمات اليابانياة. ويشير عساف (170:2014)، والمنظمة العربية للتنمية الإدارية (22:2016) لسياسة العلماء اليابانيين في الجمع والانتقاء من مبادئ النظريات الأخرى كنظرية الإدارة العلمية ل (تايلور)، ونظرية العلاقات الإنسانية ما يناسب المجتمع الياباني، وتعديل ما يلزم لخدمة بئئة المئة العمل. فقد وضيع وليم أوتشي نظرية Z لتطبيق طريقة الإدارة اليابانية في خارج اليابان، وبين أن فن الإدارة اليابانية لفترة ما بعد الحرب العالمية الثانية

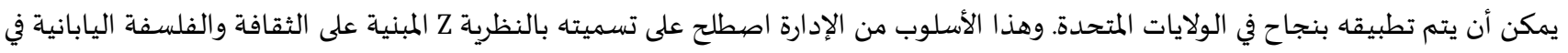

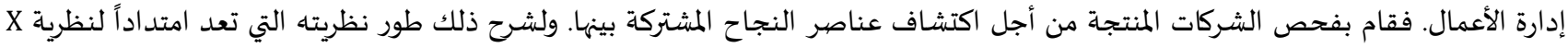

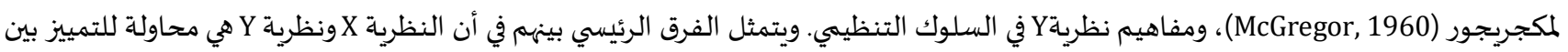
الشخصية وأساليب القيادة للمشرف الفردي، في حين أن نظرية Z معنية بثقافة المنظمة بأكملها. أي أهنا تركز على الثقافة التنظيمية والطريقة التي

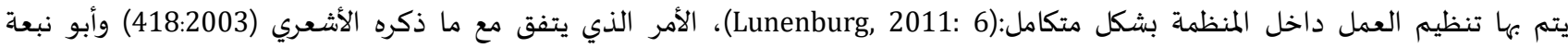

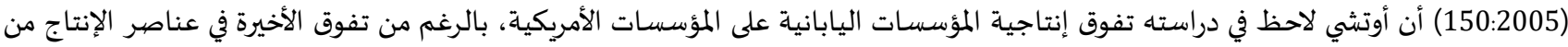

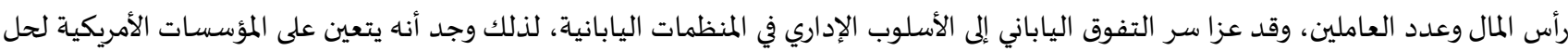

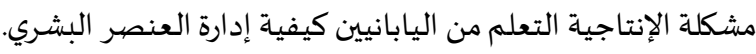
وذكر دودين (107:2014) أنه يُنظر إلى المؤسسات اليابانية على أساس أنها مؤسسة عائلية يتصرف أفرادها إدها وكأهم ينتمون إلى عضوية عائلة

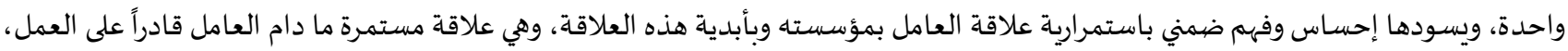

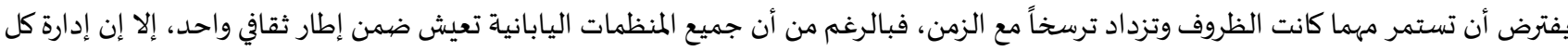

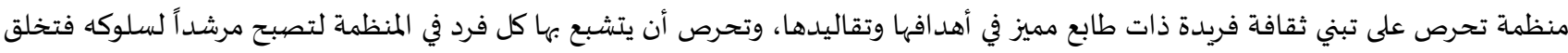
نوعاً من التكامل بين الأفراد والمنظمة.

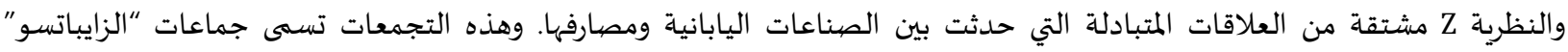
Zaibatsu صناعي تعتبر "زايباتسو" هي احتكار ثنائي يعمل بثقة وتعاون تام، وينتج عنها إنتاج فاعل.

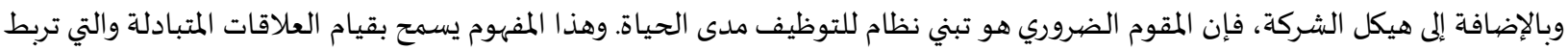
النظام معاً. وفي الواقع يبدأ تطبيق نظام التوظيف مع تعليم الأطفال، وينتج عن ذلك منافسة شديدة للقبول في أفضل المدارس العامة. ويتم القبول عن طريق نظام قومي للاختبارات في أفضل الكليات التي تخضع للمراقبة الصارمة، ومن هذه التوات الكليات تقوم “الزايباتسو” بانتقاء موظفيها من هذه

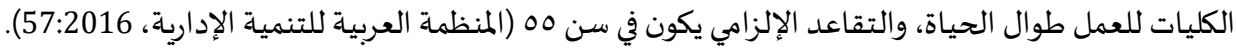

مبادئ نظرية Z في الإدارة اليابانية: أشار الأشعري (418:2003) وحكيم (544:2010) ودودين (109:2014)، وعساف (386:2014) إلى أهم المبادئ التي تشملها نظرية Z كما يلي: 
الثقة Trust: يذكر أوتشي أن الشركات اليابانية تمكنت من غزو الأسواق العالمية نتيجة لزيادة إنتاجها القائم على نظام إداري يحرص على توفير الثقة المتبادلة بينه وبين موظفيه الذين يحرصون على تحقيق أهداف الشركة كثقتهم في تحقيق أهدافهم، لقناعتهم بأن الشركة تقوم بتعويضهيم

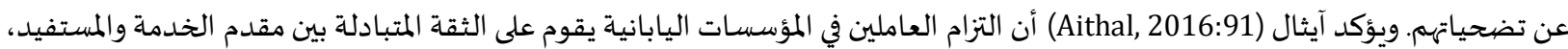
وتعتمد هذه الثقة على مصيداقية الوعود سواء المعلن عنها أو المتضمنة. ويرى ليننبيرغ أهمية الذاكرة التنظيمية في الإدارة اليابانية، فيجب أن يتذكر الرؤساء جهود الموظفين وأي جهود أو أوقات تم بذلها. فالموظف يجب أن يتأكد من الاعتراف بهذه الجهود ومكافأتها؛ مما يعزز لدى الموظفين من الثقة بوجود إنصاف في النهاية (Lunenburg, 2011:9). حدة الذهن / الحذق والمهارة Subtlety: وهذه خاصية مهمة يجب توافرها في شخص الرئيس، فهها يتمكن من التعامل مع مرؤوسياه بصورة إيجابية لأن عملية إدارة العلاقات بين الناس بصفة عامة، وبين الموظفين رؤساء ومرؤوسين بصفة خاصةة، عملية معقدة تحتاج إلى براعة (الحذق) وفن (المهارة)، وهما من الوسائل التي تؤثر على مستوى الإنتاجية إيجاباً وسلباً، فعندما يتعرف على موظفيه ويكسر الحواجز في علاقته

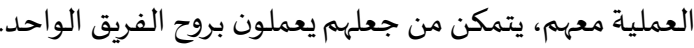

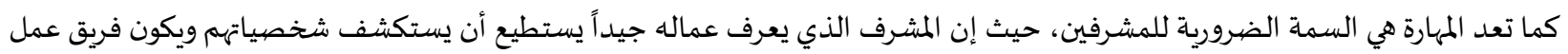
متجانس يعمل بأقصى إنتاجية ممكنة. وذلك بعكس الإدارة البيروقراطية والتي قد لا تدرك هذه الفوارق. الألفة والمودة Intimacy: يشير أوتشي هنا إلى أن طبيعة المجتمع الياباني المترابط مهدت لضرورة اهتمام الرؤساء بمرؤوسيهم والبعد عن الأنانية، فشاع بين صفوفهم صفة التقارب، ونشأت بينهم معرفة وصداقات ملحوظة، لأن الثقة والإنتاجية تسيران معاً. كما إن الاهتمام والدعم والعطف والتأييد الذي يتم من خلال تكوين علاقات اجتماعية وثيقة يجعل الحياة سهلة ومريحة والعمل بمودة

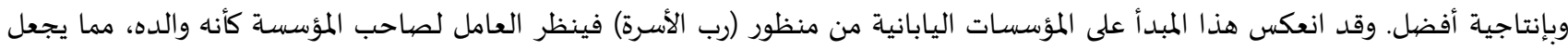
العلاقات الإنسانية المبنية على الاحترام المتبادل والتقدير تسود الأجواء. ويمكن الخلوص لتوجه نظرية Z في مجملها إلى نشر ثقافة العمل الجماعي القائم على اكتساب الثقة والمودة.

خصيائص وسمات نظرية Z: احتفظت نظرية Z بالعديد من سمات نظرية الإدارة اليابانية، ومن أهم هذه السمات كما أشـار لها مجموعة من الكتاب والمؤلفين ومنهم الأشعري

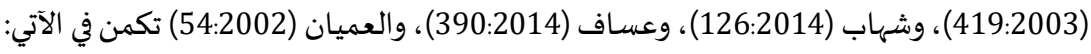

التوظيف مدى الحياة Job long- Life أي أن يبقى الموظف في وظيفته مدى الحياة، فما أن يتم تعيين الفرد، فإنه يتمتع بوظيفة دائمة في معظم

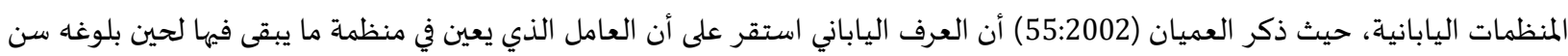
التقاعد. ولا يتم الاستغناء عن العامل الياباني من المنظمة التي يعمل فيها إلا لأسباب جوهرية كتدهور حالته الصيات الصحية، أو اتخاذ إجراءات تأديبية

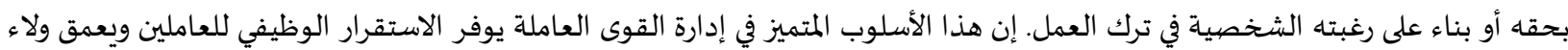

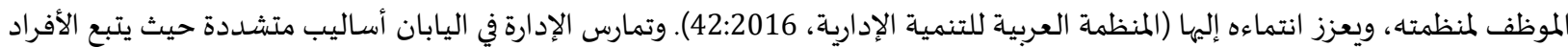

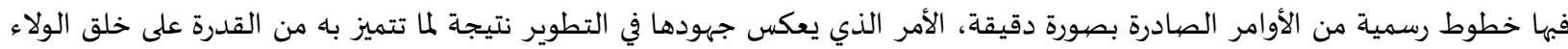
والانتماء للمنظمة كون التوظيف يستمر طوال الحياة، وكذلك يتم اتخاذ القرارات بصورة جماعية كصورة من صور المشاركة. أن الأخذ بمفهوم

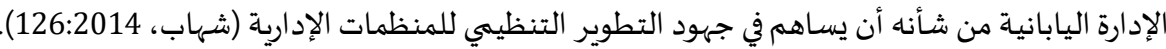

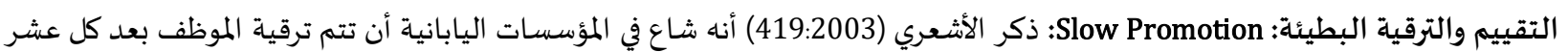

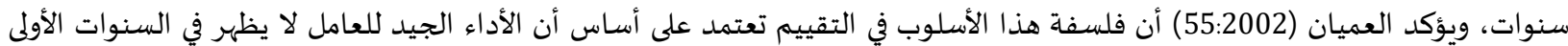

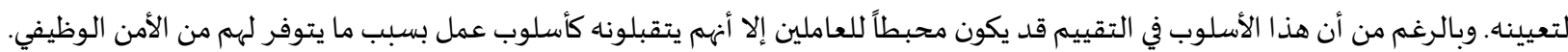
كما يشير دودين (6:2014) إلى أن مفهوم الترقية يطبق على أساس الأقدمية، وعدم التسرع بالتقييم والترقياة، فيحصل الموظف الياباني على الترقية بحسب الفترة التي يقضيها داخل المنظمة بالتركيز على تطوير مهاراته المهنية. وتطبق نفس الطريقة فيما يتعلق

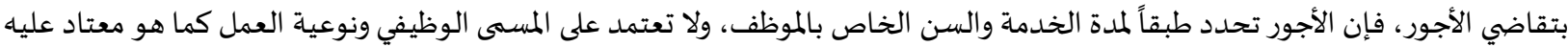

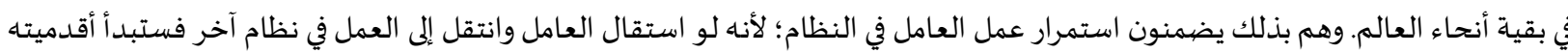
من نقطة الصفر، وبالتالي يتأخر في تقدمه الوظيفي. عدم التخصص في المهنة Job Specialty: ذكر الأشعري (419:2003) أن ذلك يعني تنقل الموظف في العديد من الوظائف والأعمال ضمن نفس

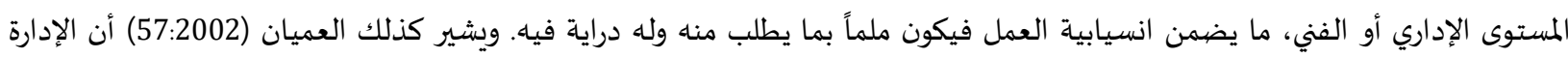
اليابانية تميزت بإتاحة تلك الفرصة للعاملين في المنظمات اليابانية، بهدف إعطاء كل عامل فرصية التعرف على المهارات والصعوبات لدى زملاء 


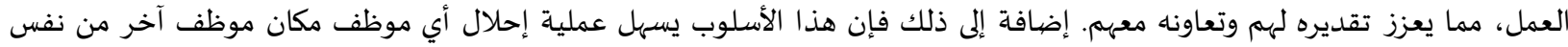

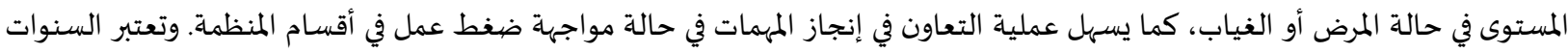
العشر الأولى فترة تدريبية، حيث يتم نقل الموظف كل ستة أشهر أو 12 شهرًا حتى يعتاد على أقسام الشركة (المنظمة العربية للتنمية الإدارية،

(48:2016

وهو ما أشار لأهميته المزيد (15:2018) في الحصول على الخبرة وتنويع التشكيل الأساسي للمعرفة لدى الموظفين، والعمل على بناء قدرة معرفية

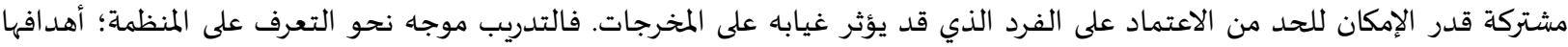

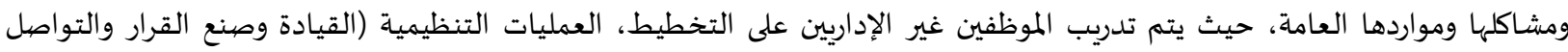
والتغيير)، وعملية ميزانية النظام، وديناميكيات المجموعة، والعديد من الأنشطة التي نادرًا ما يتعرض لها هؤلاء الموظفون (Lunenburg, 2011) عملية المر اقبة الضمنية Indirect Control: تعتمد الإدارة اليابانية أسلوب الرقابة الضمنية أو الذاتية بحيث يراقب الفرد العامل نفسها

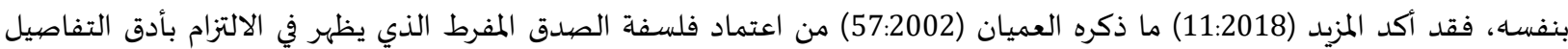

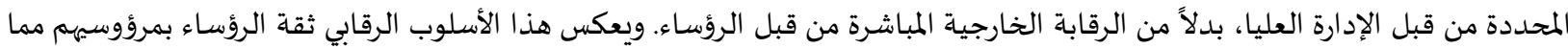

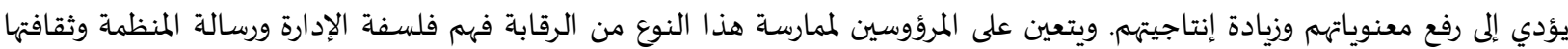

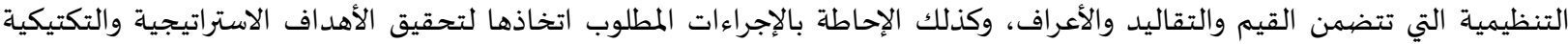
والتشغيلية. أما الأشعري (419:2002) فقد ذكر أن الرقابة الضمنية يمكن أن تتم من الخارج ولكن بلباقة ومهارة دون أن يشعر الموظف بأنها

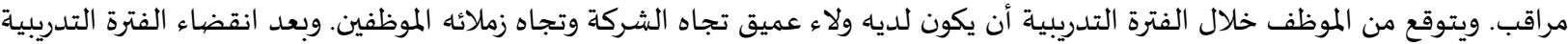

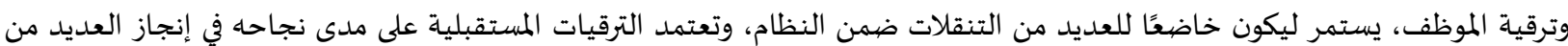

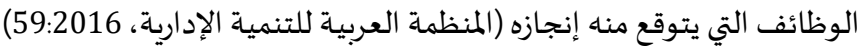
اتخاذ القرارات بطريقة جماعية Group Decision Making: يتفق المزيد (8:2018) مع المنظمة العربية للتنمية الإدارية (61:2016) في أن

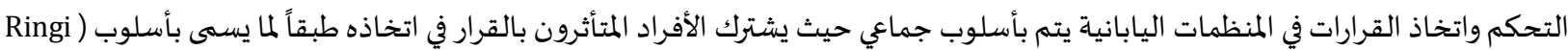

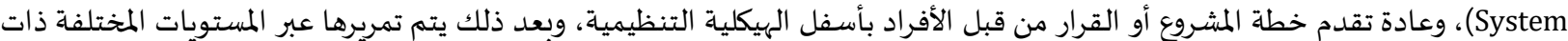

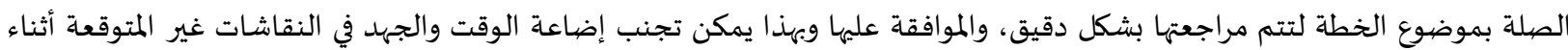

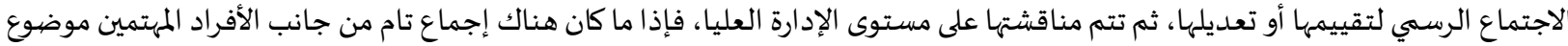

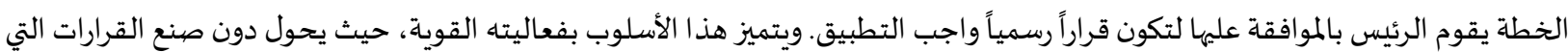

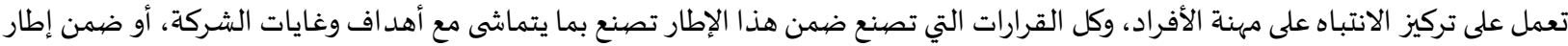

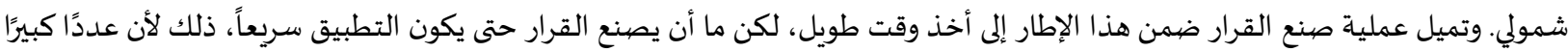
من الناس يشتركون في صنعه. ويؤكد ليننبيرغ أهمية توجه القادة لقضاء الوقت الكافي في مناقشة الأهداف مع الموظفين والمستفيدين، وفهم نظام الحوافز المتاح للموظفين في وظائفهم ومساعدتهم على ترشيد هذه الحوافز حتى يتمكنوا من الوثوق بها، مما يمكن المسؤولين دعوة المرؤوسين لمشاركة التحكم في القرارات التي ستؤثر على طريقة أدائهم (Lunenburg, 2011:8). المسؤولية الجماعية Overall Responsibility: إن من أبرز خصائص الإدارة اليابانية التأكيد على روح الجماعة والعمل كفريق واحد، وهذا

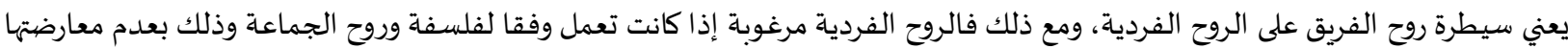

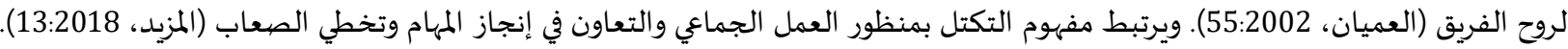

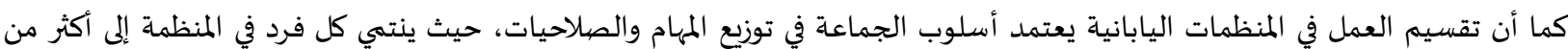

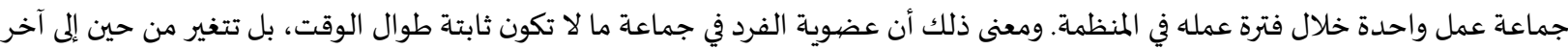

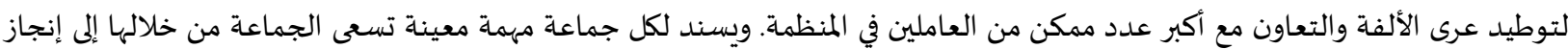

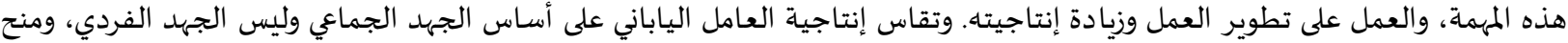

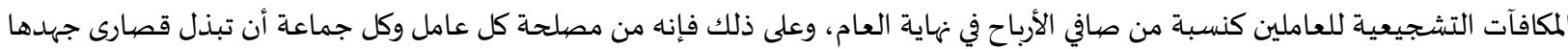
بغية زيادة الإنتاج وتطويره، لأن زيادة الإنتاجية وزيادة الدخل يعودان بالنفع العام على جميع العاملين وليس فئة محددة منهم (دودين،

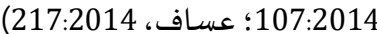

ه الاهتمام الشامل بالأفراد Comprehensive Care for Employees: وهي تعني كما يراها الأشعري (217:2014) (419:2003) العناية بالموظف ليس فقط في شؤون العمل، بل حتى خارج العمل كدعوة أسرته وذويه في المناسبات. كما يؤكد العميان (56:2002) وعساف (213:2014) أن الإدارة اليابانية 


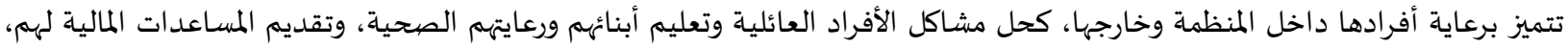

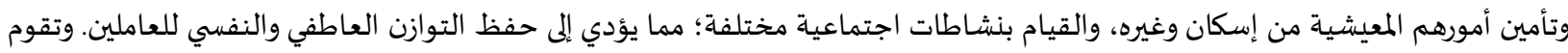
الإدارة اليابانية بهذه النشاطات على اعتبار أن ما يحصل للفرد من ضغوط المعادين خارجية يؤثر على أدائه في في المنظمة، ولقد بينت الدراسات أن المنظمة

اليابانية تضفي على نفسها السمة العائلية.

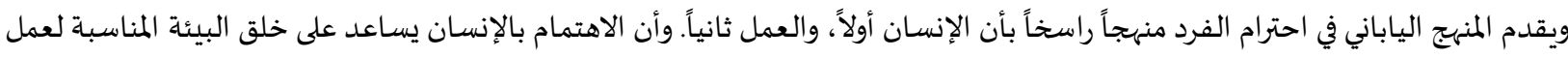

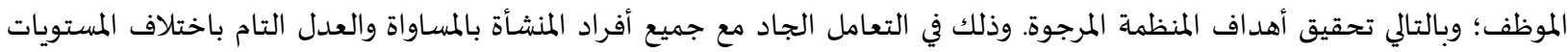

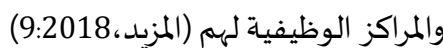

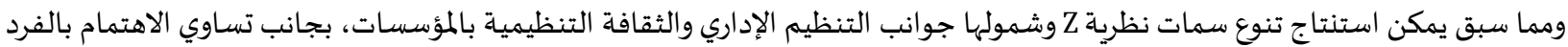

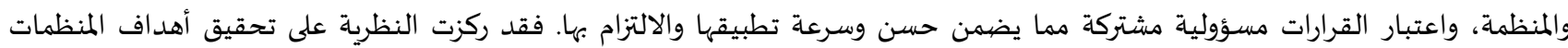
بمشاركة الأفراد اهتماماً وتقديراً وزرعاً للشعور بالشراكة والمسؤولية لدى العاملين، مما يدل على تقاطعها في كثير من الجوانب مع الإدارة في الإسلام.

التأصيل الإسلامي لمبادئ وخصائص نظرية Z في الإدارة اليابانية:

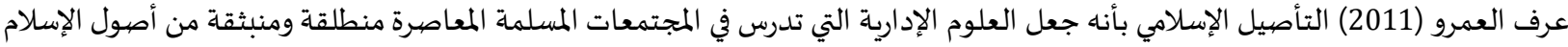

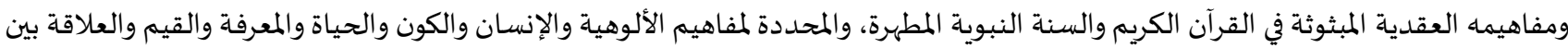

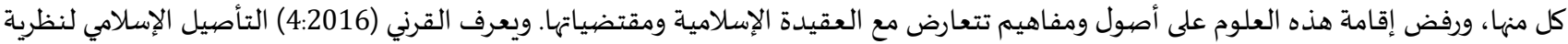

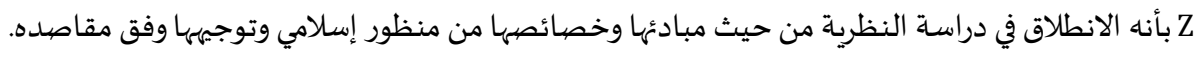

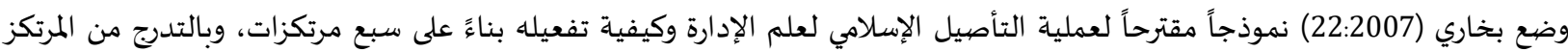

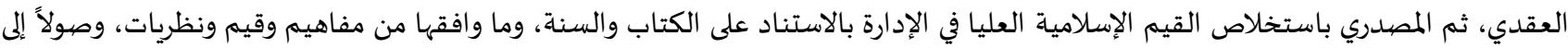

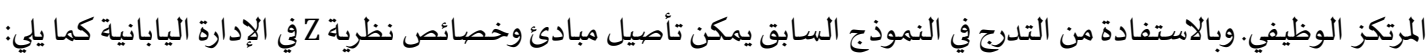

أولاً التأصيل الإسلامي لمبادئ وخصائص نظرية Z في الإدارة اليابانية وفقاً للقرآن الكريم والسنة النبوية الشريفة:

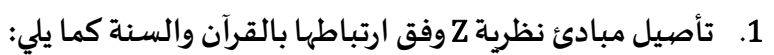

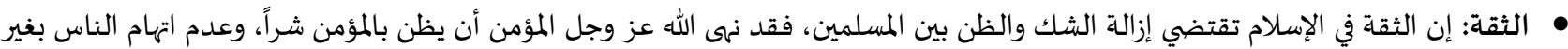

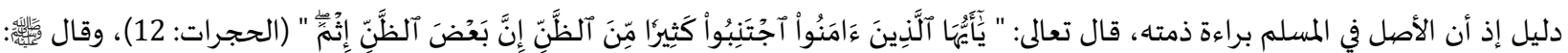

$$
\text { "حسن الظن من حسن العبادة" (رواه أحمد). }
$$

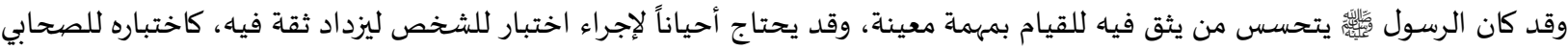

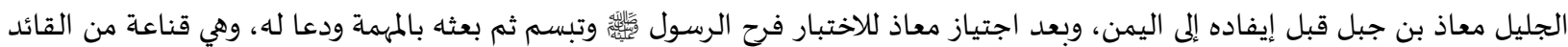

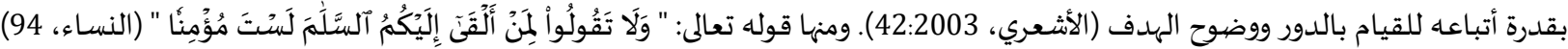

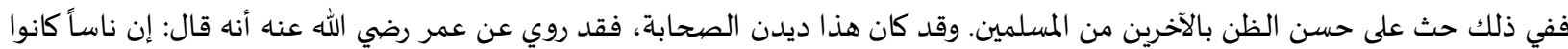

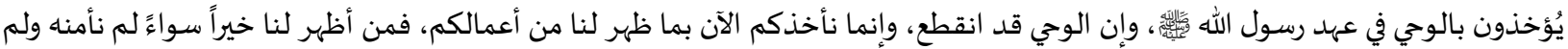

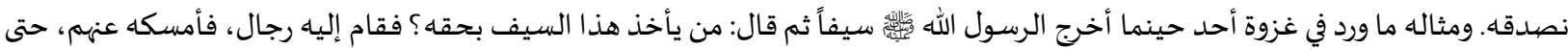

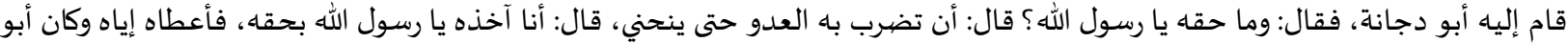

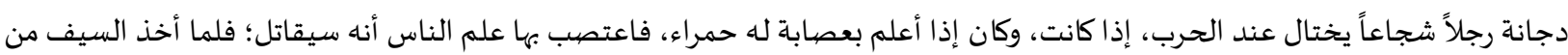

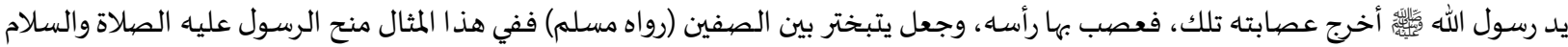

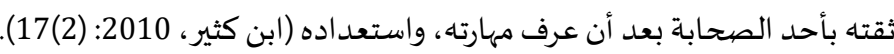

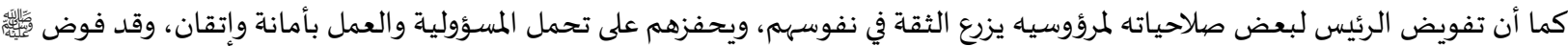

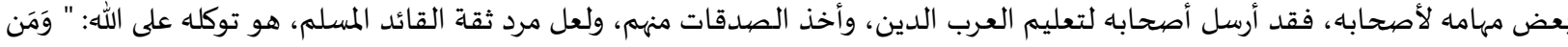

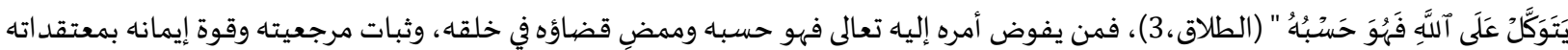

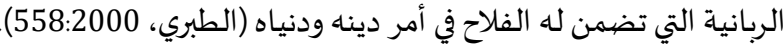

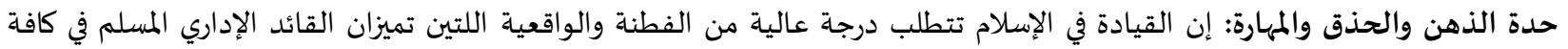

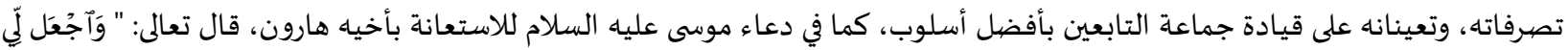

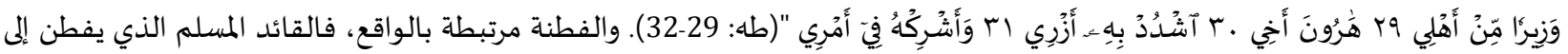


واقعه واحتياجاته. وتأكيداً على أهمية هذا المبدأ فقد عدّ القرني (26:2016) الفطنة والكياسة الركن الثالث من أركان القيادة الإدارية في الإسلام،

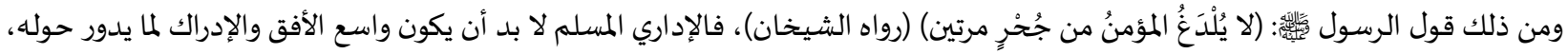

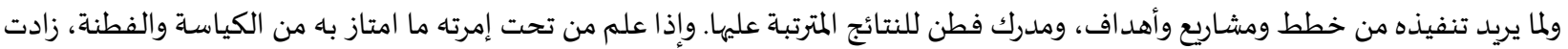

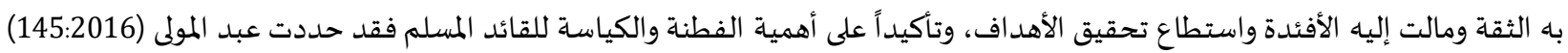

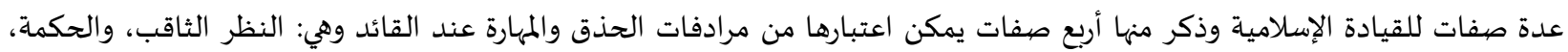

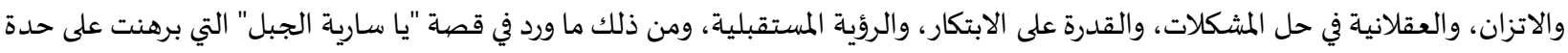

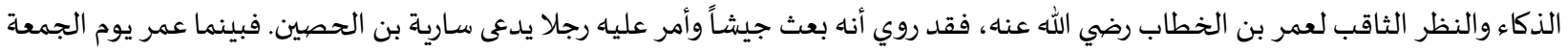

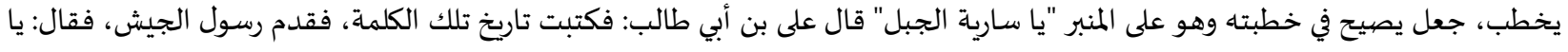

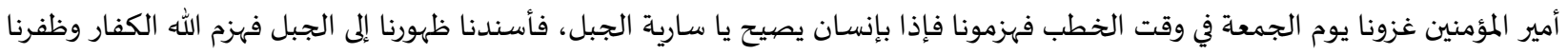

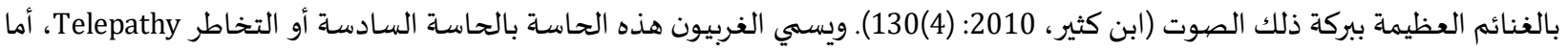

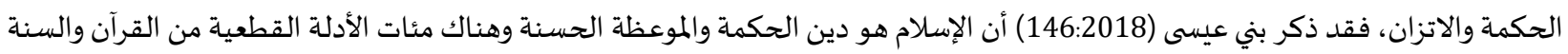

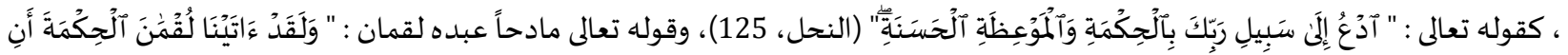

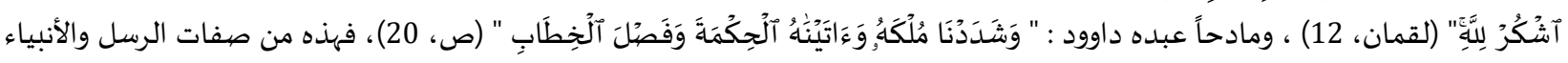

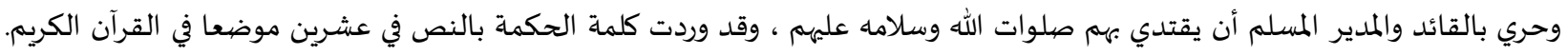

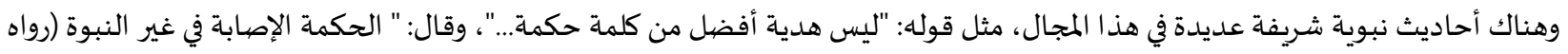

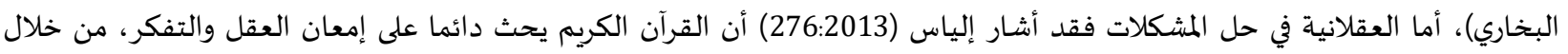

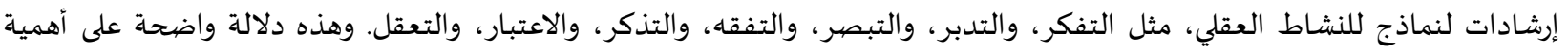

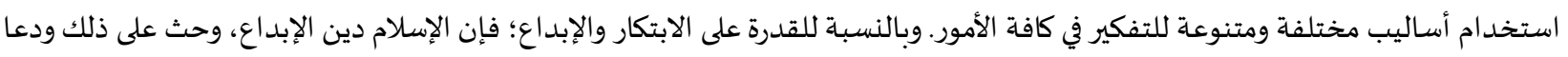

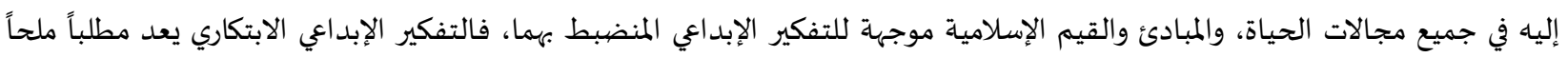

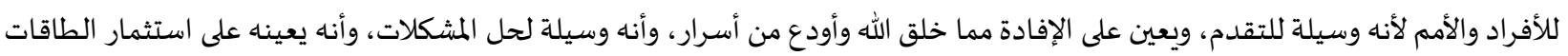

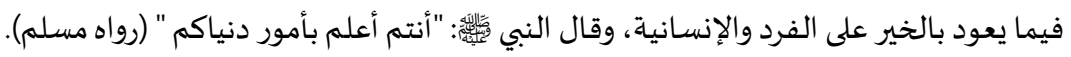

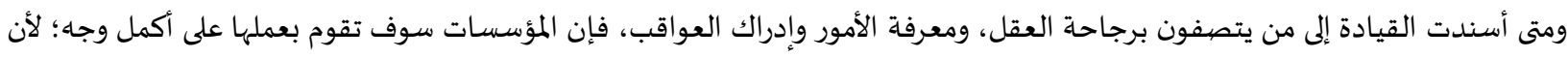

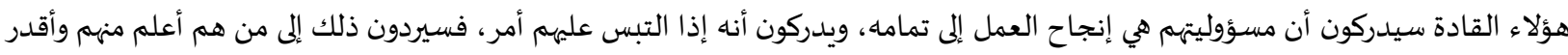

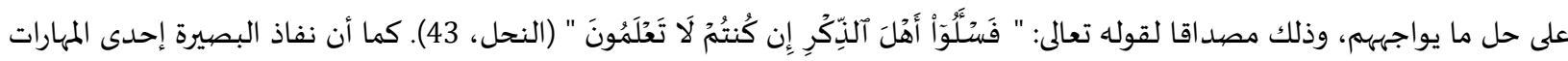

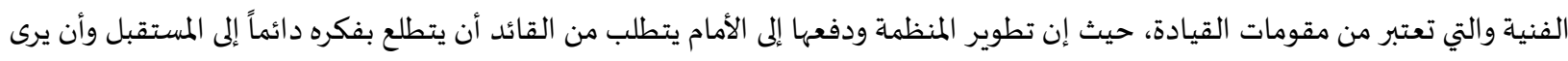

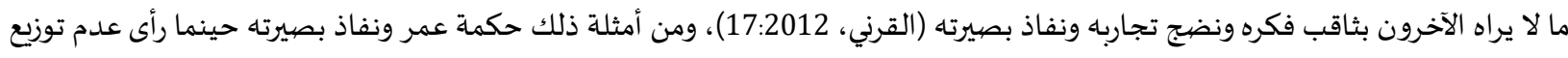

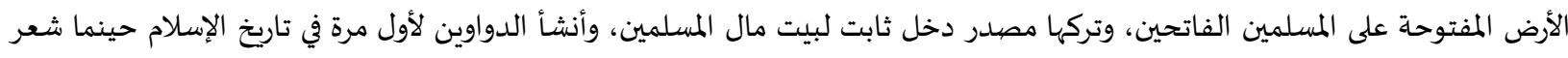

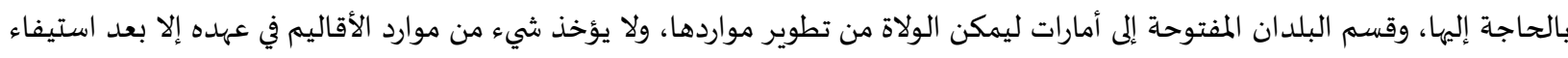

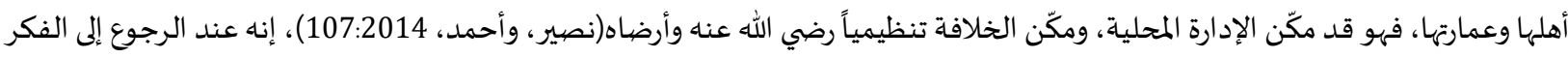

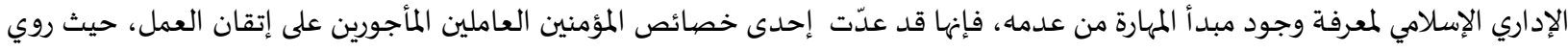

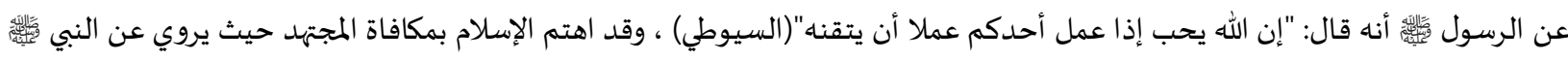

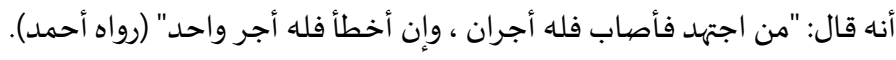

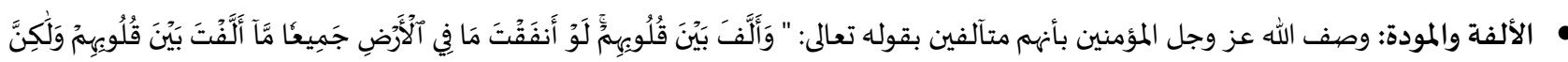

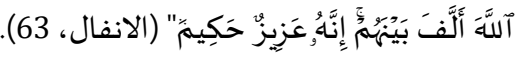

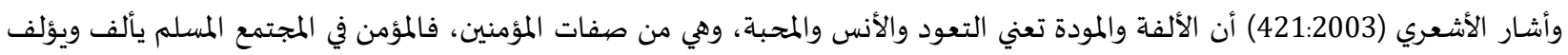

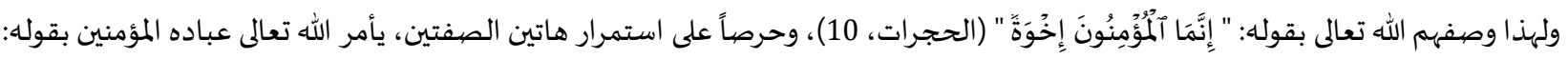

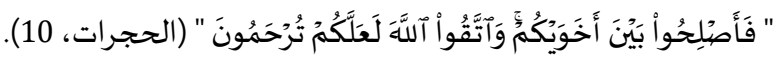

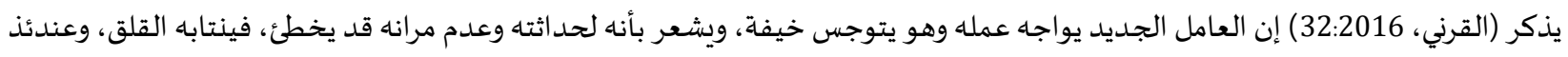

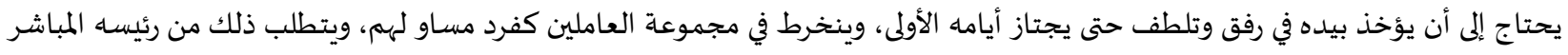

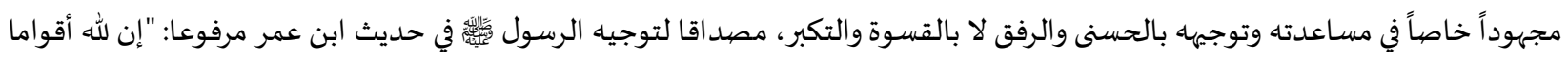

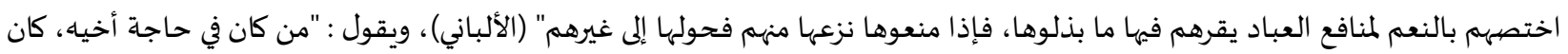




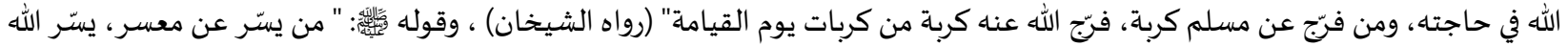

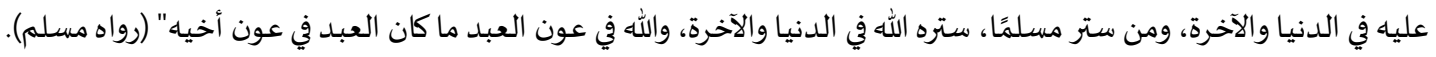

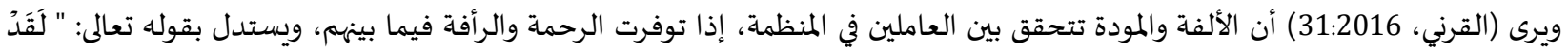

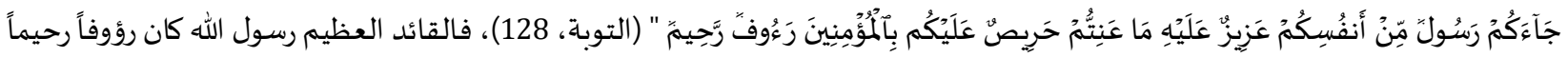

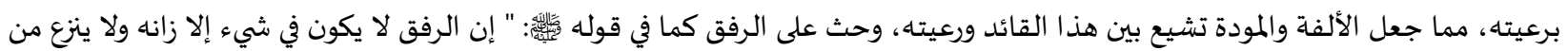

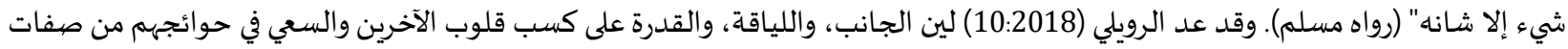

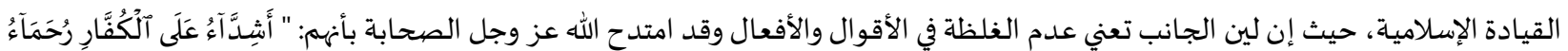

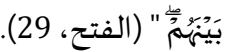

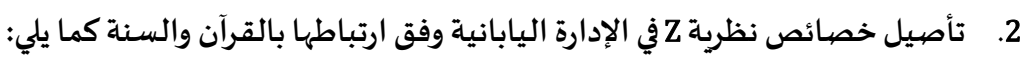

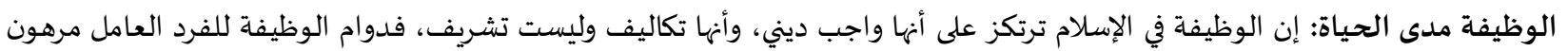

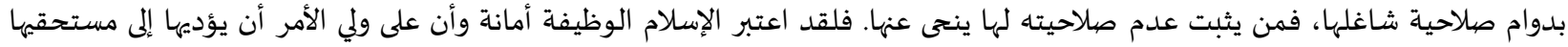

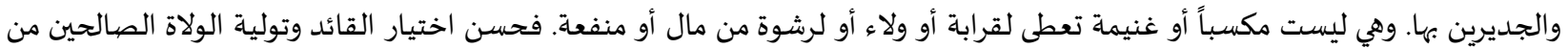

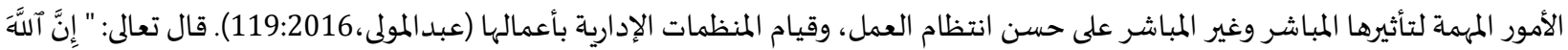

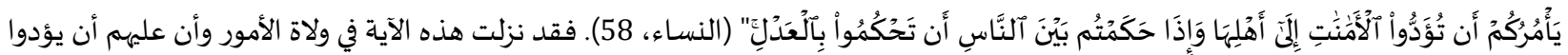

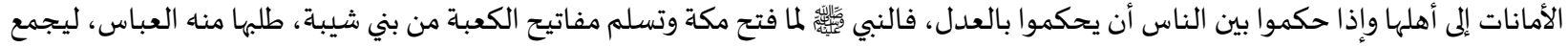

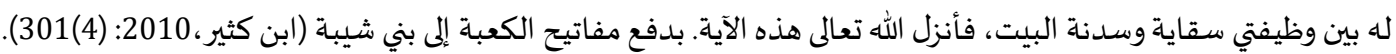
• التقييم والترقية البطيئة: لا تتم الترقية في معظم المؤسسات اليابانية إلا كل عشر سنوات، وهذا الإجراء يطبق على جميع العاملين في المؤسسة

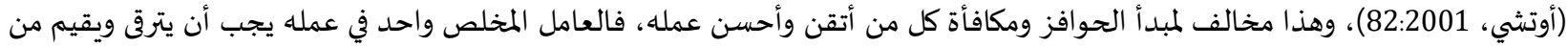

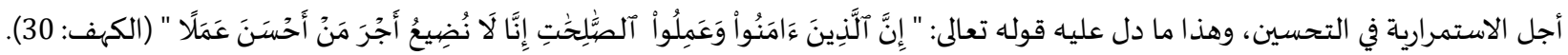

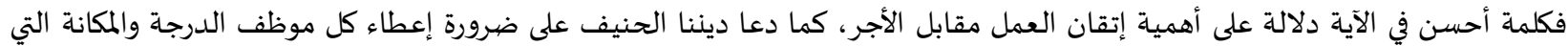

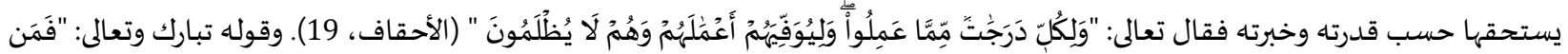

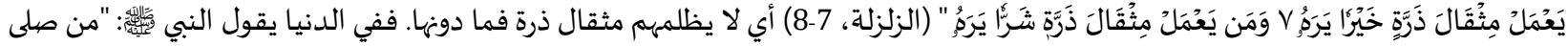

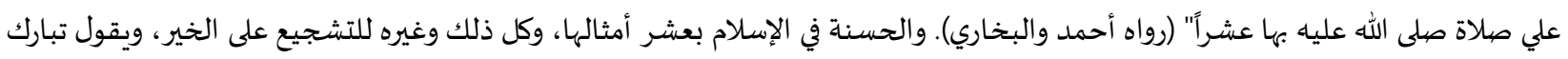

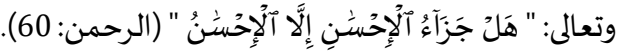
عدم التخصص في المهنة: أي أن الموظف يمارس أكثر من مهنة وينتقل من قسم إلى آخر وبذلك للاستفادة بهاه في خدمة جميع أقسام المؤسسة التي

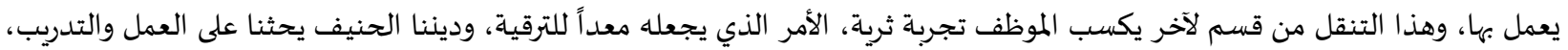

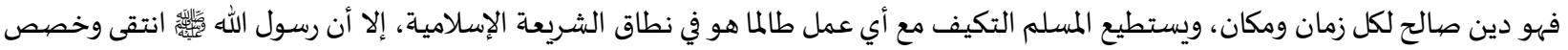

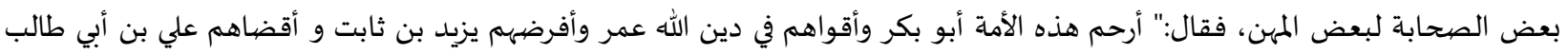

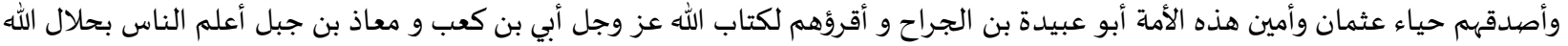

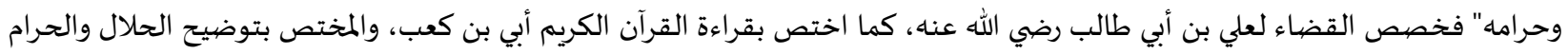
معاذ بن جبل رضي الله عنهم وأرضاهم (رواه أحمد وابن ماجها). ه اتخاذ القرارات بطريقة جماعية: تعتمد المؤسسات اليابانية على القرار الجماعي المشترك، فعندما يراد اتخاذ قرار مهم في المنظمة اليابانية، يتم

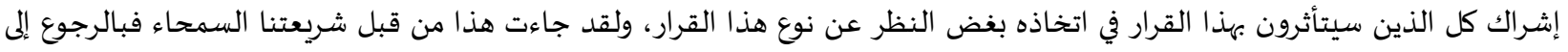

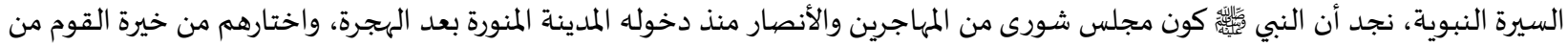

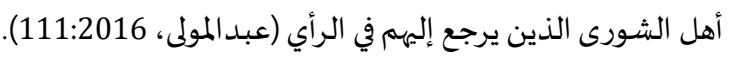

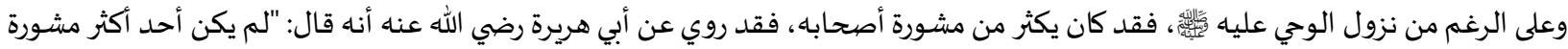

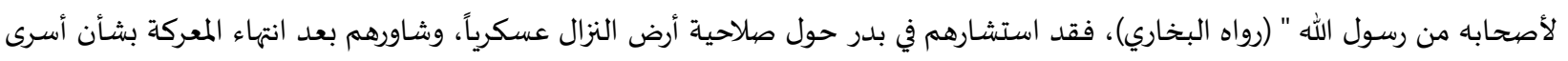

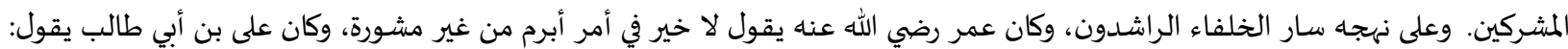

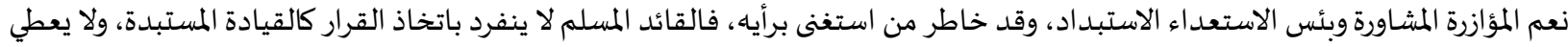

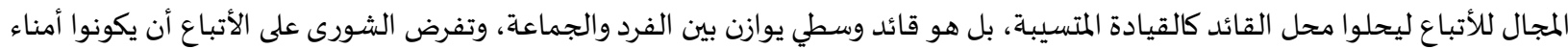

مخلصين في مشورتهم (نصير، أحمد، 195:2014). 
• الاهتمام الشامل بالأفراد: تهتم المؤسسات اليابانية بشمولية العناية والاهتمام بالموظفين، وتنعكس هذه الصفة الشمولية والاهتمام الكلي على المادي

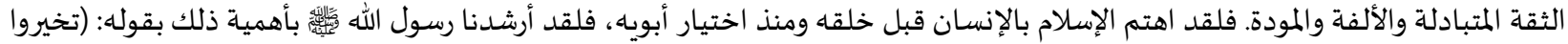

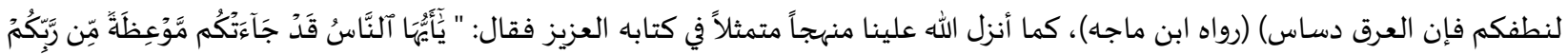

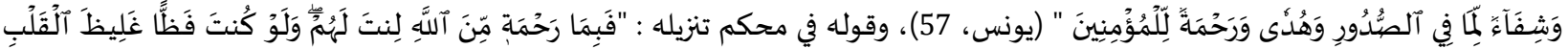

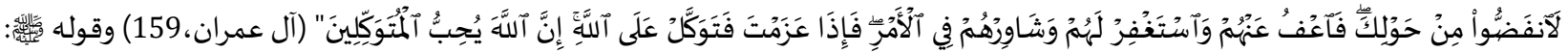

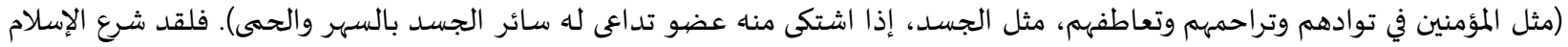

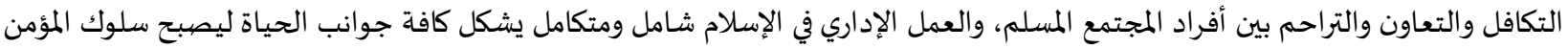

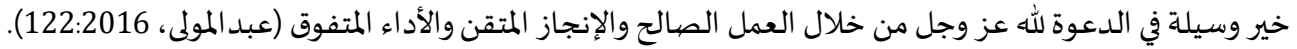

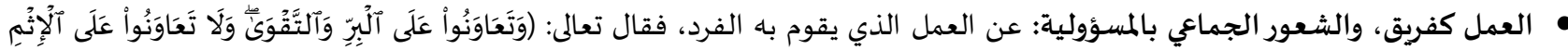

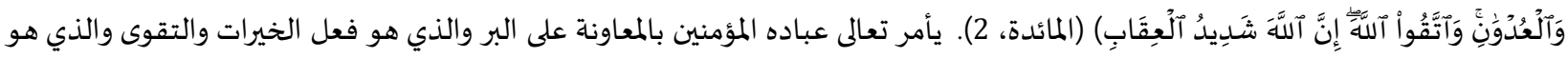

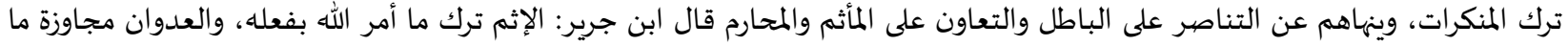

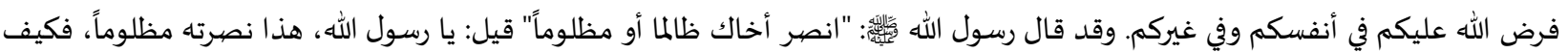

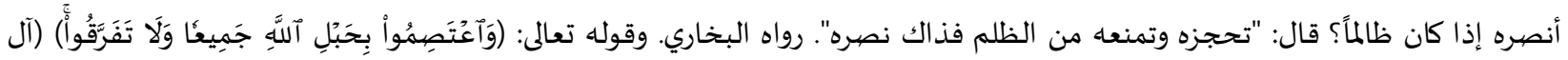

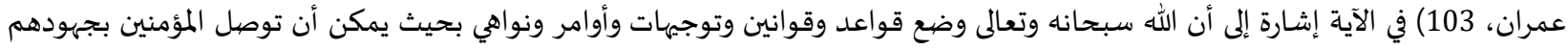

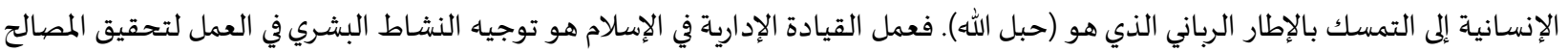

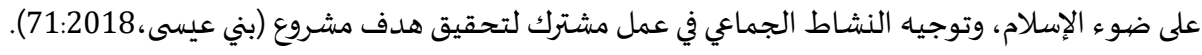

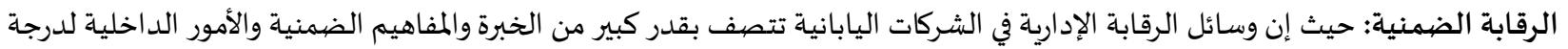

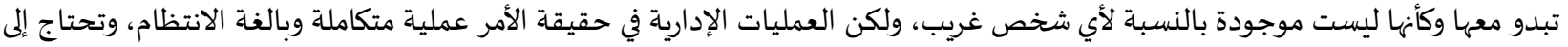

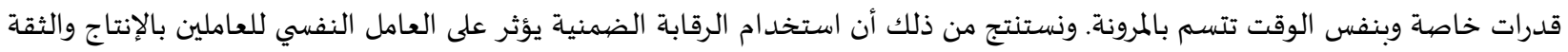

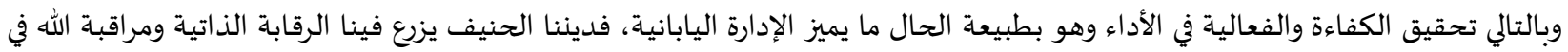

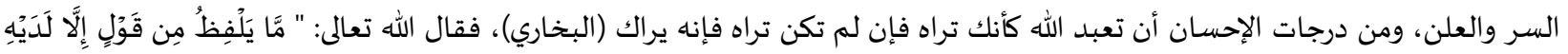

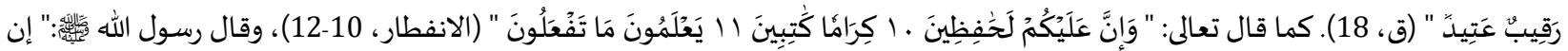

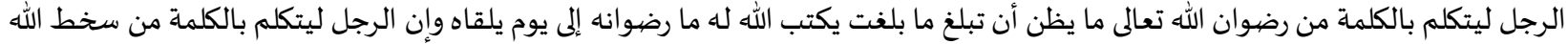

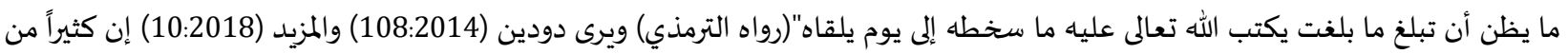

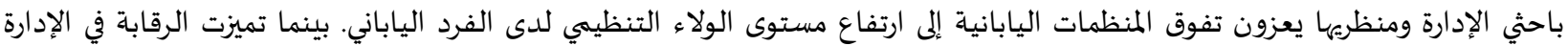

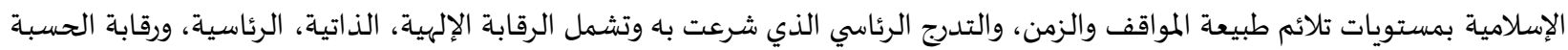

والنظام الإداري (بني عيسى، 172:2018).

ثانياً: التأصيل الإسلامي لمبادئ وخصائص نظرية Z في الإدارة اليابانية وفق ارتباطها بمقاصيد الشريعة الإسلامية: 1. تأصيل مبادئ نظرية Z وفق ارتباطها بمقاصد الشريعة الإسلامية:

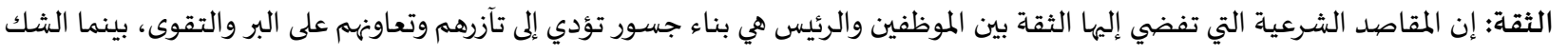

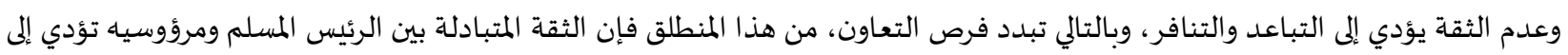

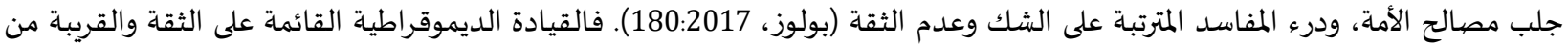

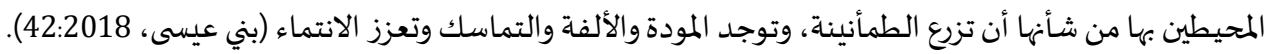

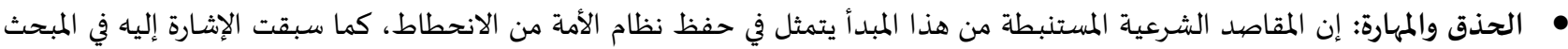

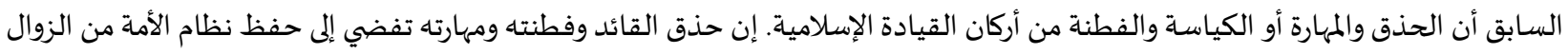
(إلياس، 269:2013).

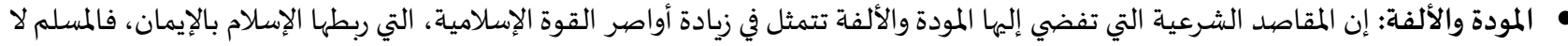

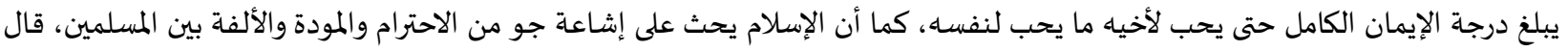

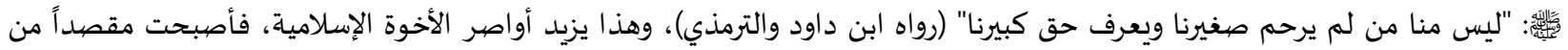


مقاصد الشريعة الإسلامية، وكما سبق إيراده في المبحث السابق، فإن ذلك يزيد استقرار المنظمات الإسلامية، وبهذا يتحقق حفظ مال الأمة،

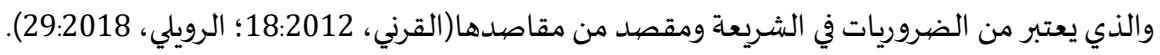
2. تأصيل خصيائص نظرية Z وفق ارتباطها بمقاصيد الشريعة الإسلامية:

ه الوظيفة مدى الحياة: هذا المبدأ لا يتفق تماماً مع ما جاءت باء الإدارة الإسلامية في نظام التوظيف في الإسلام، ولذلك فإن الوظيفة مدى الحياة لا

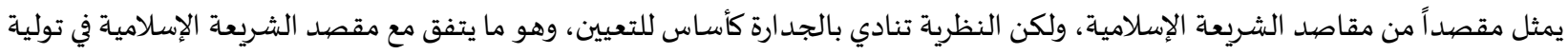
الأصلح (حكيم، 545:2010؛ أبو شادي، 215:2017). ه التقييم والترقية البطيئة: هذا المبدأ لا يتفق تماماً مع ما جاءت به الإدارة الإسلامية في نظام الترقية في الإسلام، فالتقييم يعتمد على الجدارة

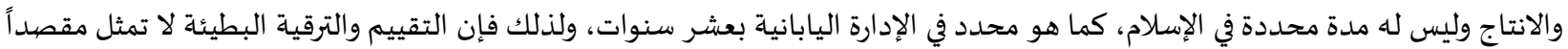

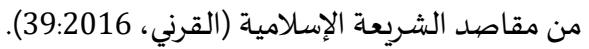
عدم التخصص في المهنة: إن هذا المبدأ أيضاً لا يتفق تماماً مع ما جاءت به الإدارة الإسلامية، حيث شجع الإسلام في كثير من الآيات والأحاديث

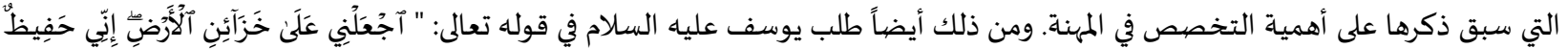
عَلِيمّ" (يوسف، 55) مما يدل على التخصيص (أبو شـادي، 218:2017؛ بني عيسى، 151:2018).

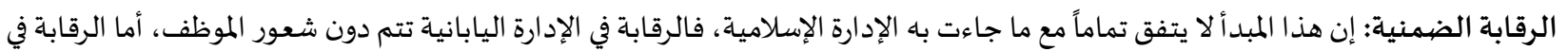
الإسلام فتنقسم الى: رقابة ذاتية تنبع من داخل الفرد لكونه مسلماً، فالأمانة والاخلاص من مبادئه الإسلامية التي يحافظ عليها لينال أجره من الله،

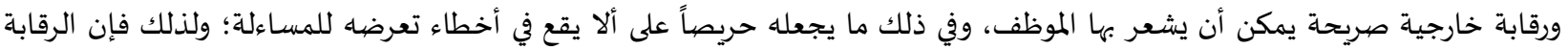

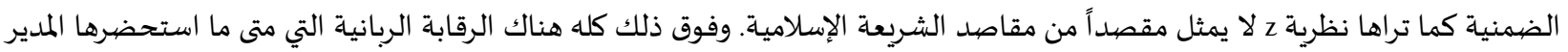

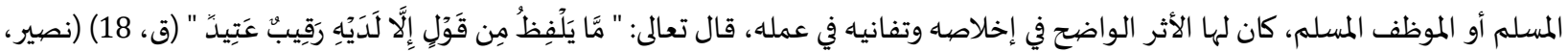
أحمد، 210:2014).

• اتخاذ القرارات بطريقة جماعية: يتوافق هذا المبدأ مع أهمية الشورى عند اتخاذ القرار، فالقائد المسلم يجب أن يستشير جماعتاه، لأن العقل

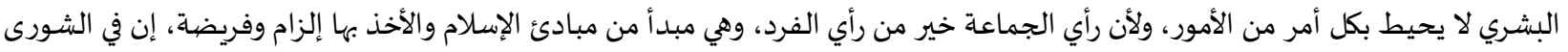

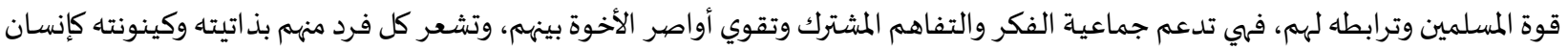
مكرم مقدر. من هذا المنطلق فإن المقاصد الشرعية التي يفضي إلهها مبدأ اتخاذ القرارات بطريقة جماعياة، هي زيادة قوة الأمة وحفظ نظاهي نهاهيا،

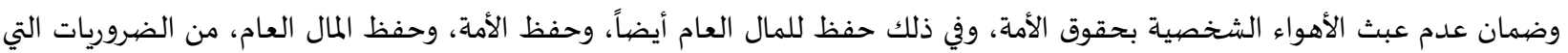

حثت الشريعة على حمايتها (ملائكة، 2013: 508). المسؤولية الجماعية: إن المقاصد الشرعية التي يفضي إلها مبدأ المسؤولية الجماعية، يتمثل في حفظ الأمة من تفشي الفساد فيها، فكل فرد

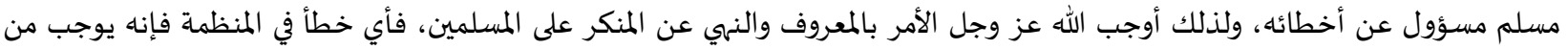

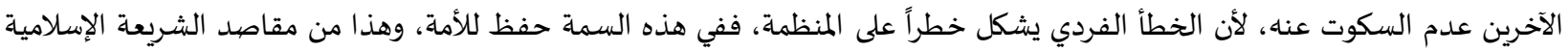

(نصير، أحمد، 212:2014).

• الاهتمام الشامل بالفرد: إن المقاصد الشرعية التي تفضي إليها هذه السمة، هي في شعور الموظف بالاستقرار والاطمئنان، نتيجة للعناية

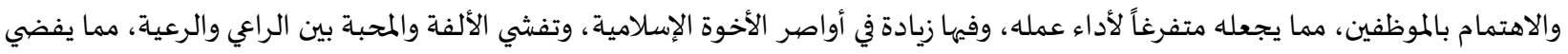
إلى استقرار الأمة وحفظ نظامها من الزوال، وفيها حفظ لحقوق الموظف المسلم المالية وغيرها، وهما مقصديدان من مقاصيد الشريعة الإسلامية.

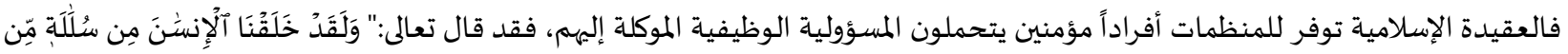

طِين " (المؤمنون، 12) فقد عرف الإسلام الإنسان بأنه مخلوق من طين وفكر وروح (بني عيسى، 64:2018؛ حكيم،

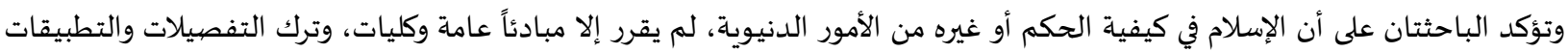

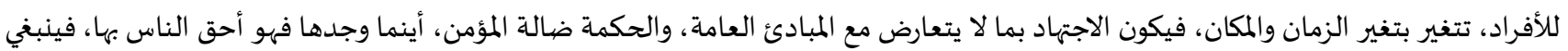
على المسلم البحث عن كل ما هو مفيد ونافع، حتى لو وجد في ثقافات أخرى، مالم توجد موانع عقدية تمنع من تبنيها. ثالثاً: نظرية Z في الإدارة اليابانية وفقاً للمرتكز الوظيفي: تتأثر الإدارة التربوية بالعديد من العناصر المتداخلة نتيجة ارتباطها بالعنصر البشري، والتفاعل المستمر بين عناصر بيئتها الداخلية وتداعيات

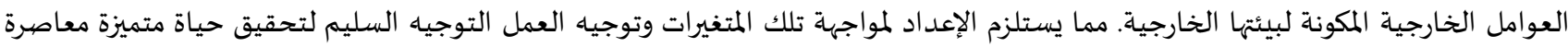

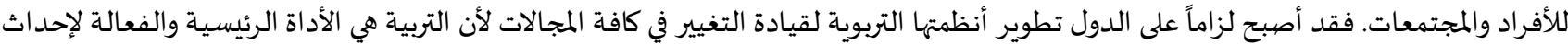


وتوجياء التغير الاجتماعي للاتجاه الإيجابي الصحيح المرغوب فياء لتحقيق آمال وطموحات الأمم والشعوب (سليم، 7:2019). عكست النظريات التربوية

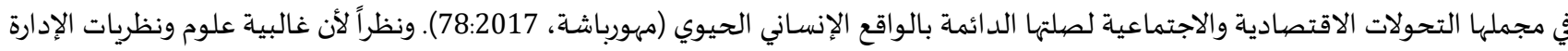

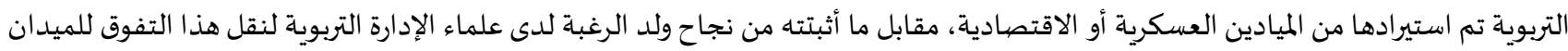
الإداري التربوي.

ويتوافق ما أورده أبو نبعة (2005: 163) من أهمية تبني الأسلوب الياباني في الإدارة لزيادة الإنتاج في المصانع الأمريكية؛ ما مع ما أشارت إليه سليم (8:2019) كالدافع الرئيسي وراء إجراء معظم الدول تغيرات جذرية تربوية في أنظمتها التعليمية لتواكب وتتلاءم مع المستجدات والمتغيرات التي لا يمكن

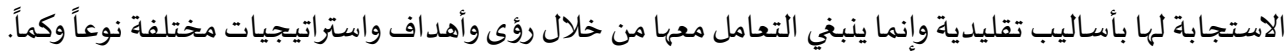
حيث اهتم النظام التربوي في اليابان بتربية الطفل الياباني على الأخلاق والقيم والتقاليد الحسنة، لإنتاج فرد يتمتع بالصلاح وروح المواطنة، يعمل

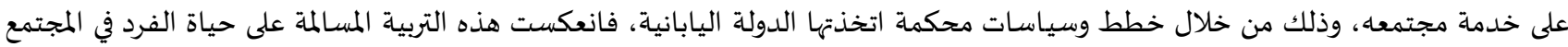
الأكبر ، سواء في تعاملاته اليومية أو في عمله. حيث يطبق الفرد نتاج التربية الصحيحة التي تلقاها كالآخرين، والتي تنتج في نهاية الأمر تعاطفاً وتكافلاً بين

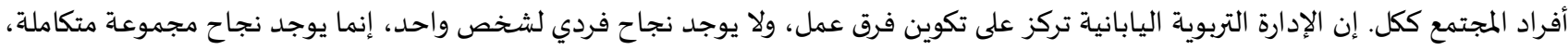

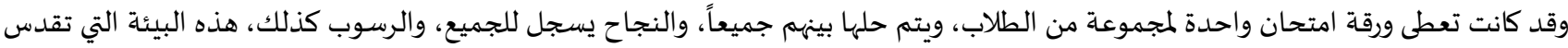

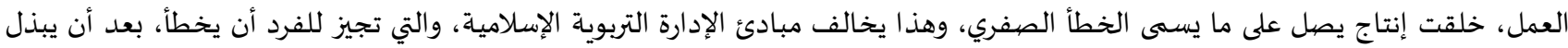

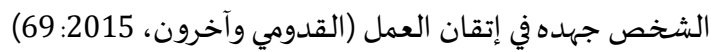
إن تطبيق مبادئ وأسس نظرية Z في الإدارة التربوية يتطلب من الإداري التربوي بشكل عام ومن مدير المدرسة بشكل خاص التركيز على احتياجات المعلمين والإداريين والطلاب، والنظر إليهم كأعضاء أسرة واحدة، ويتوجب علئ عليه هو كرب الأسرة الاهتمام بهم وتدريبهم والعمل على ترسئ ترسيخ معايير أداء

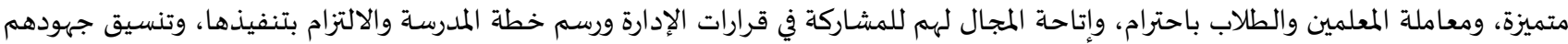

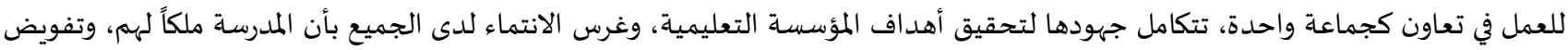
السلطات للمعلمين حسب إمكانياتهم، وتقبل الابداع والابتكارات الجديدة، وتشجيع مزاولة الأنشطة الترفيهية والاجتماعية والتثقيفية للمدرسين والتلاميذ (حكيم، 550:2010). الأمر الذي يتفق مع السعي الإسلامي لتأسيس جملة من القواعد التربوية التي توجه الفكر الإنساني، والتي تؤثر إيجاباً في

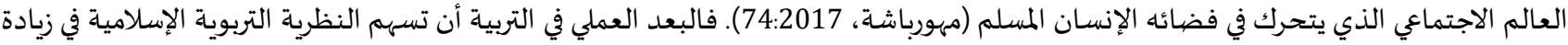
الإنتاجية التربوية ودعم الإدارة لتحقق كافة وظائفها من تخطيط، وتنظيم، وتوجياء، وتقويم لتحقيق الفاعلية والكفاءة الإنتاجية على مستوى الأفراد والمنظمات التربوية والاجتماعياة.

ومما سبق تصل الباحثتان إلى أن نجاح المنظمات التربوية يستلزم الأخذ بأصل الإدارة الإسلامي وتعميق أثرها في المنظمات الإدارية مما يعود عليها

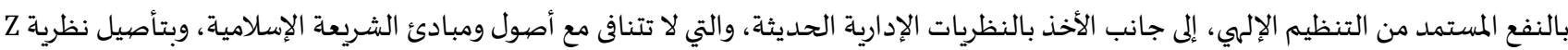

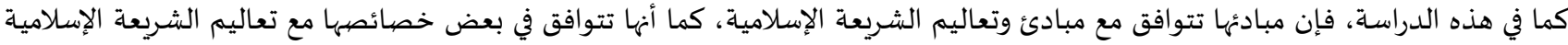

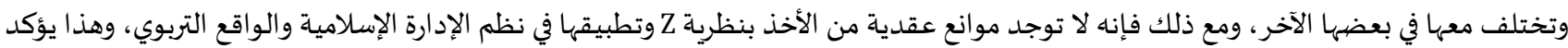
ما تدعو له هذه الدراسة من أهمية التأصيل الإسلامي للنظريات والمبادئ الإدارية الحديثة بما يضفي عليها صيفة الشرعية ويعمق العقيدة الإسلامية نصاً وتطبيقاً لاسيما في الميدان التربوي الإداري. وتتفق أهداف الدراسـة الحالية مع دراسـة القرني (2012) في التعرف على عن خلفياة، ومبادئ، وخصائص نظرية Z، وفي بيان التأصيل الإسلامي

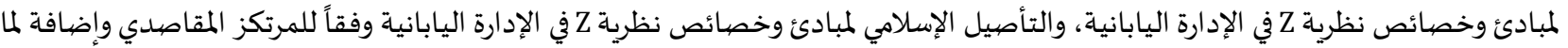

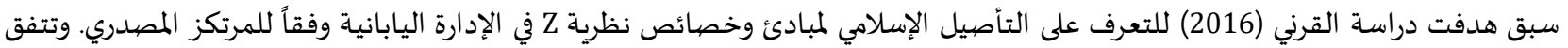

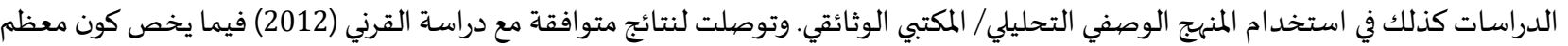

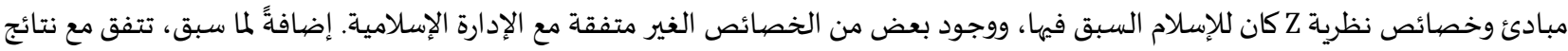

$$
\text { دراسة القرني (2016) بعدم وجود مانع عقدي في الأخذ بها والإفادة منها. }
$$

بينما تختلف في تناول دراسة القرني (2012) لمفهوم المقاصد الشرعية، والخطوات الإجرائية للتأصيل الإسلامي للعلوم، والصفات الضابطة

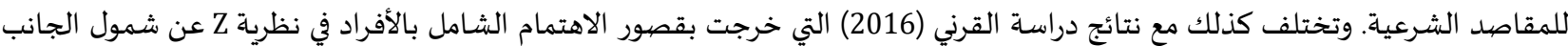
الروحي. وقد تفردت الدراسة الحالية باستعراض التأصيل الإسلامي لمبادئ وخصائص نظرية Z في الإدارة اليابانية بناءً على المرتكز الوظيفي بالإدارة

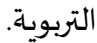


نتائج الدراسـة:

بتأصيل نظرية Z إسلامياً يمكن استخلاص النتائج التالية: أن نظرية Z اليابانية استحدثت في الأساس للوصهول لأسباب نجاح المنظمات اليابانية، مما يعزز من قوتها، وصلاحيتها للتطبيق في المنظمات

أن غالبية مبادئ نظرية Z تتوافق مع مبادئ الشريعة الإسلامية. أن جذور هذه النظرية موجودة في القرآن والسنة.

أن بعض خصائص نظرية Z ليست موجودة ضمن المقاصد الشرعية الإسلامية.

لا توجد موانع عقدية من تطبيق نظرية Z في المنظمات الإدارية الإسلامية.

إمكانية الاستفادة من تأصيل نظرية Z في الواقع التربوي العملي نظراً لما تتضمنه من توجهات ومبادئ إيجابية تدعم بيئة العمل وتحسن من إنتاجية الأفراد وفعالية المنظمات التربوية الإدارية. ويمكن تفسير النتائج بناءً على التوافق بين نظرية Z والمنهج الإسلامي من المنطلق الإيجابي للنظرية وتوجهها نحو تحسين الإنتاجية، فقد

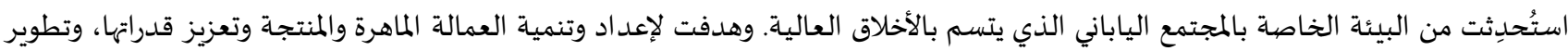
إحساس الملكية لدى الأفراد داخل المؤسسات والانتماء إليها؛ الأمر الذي انعكس بلدوره على العمل الإداري، وكان له الأثر الإيجابي على الإنتاجية والإخلاص لأهداف المنظمة. مما يتفق مع المنهج الإسلامي في تعزيز قدرات الأفراد وقوتهم البدنية والعملية المستمدة من تفضيل المؤمن القوي على المهائ المؤمن الضعيف، والحث على إتقان العمل وتجويده والسعي لتحقيق المنفعة والصالح للفرد والمجتمع، الأمر الذي يتفق مع نتائج دراسة سعد الدين

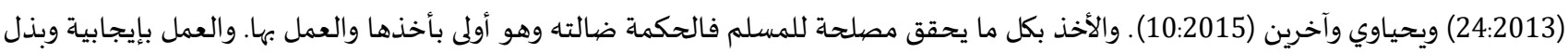

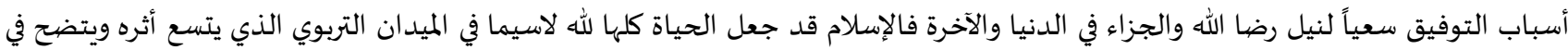

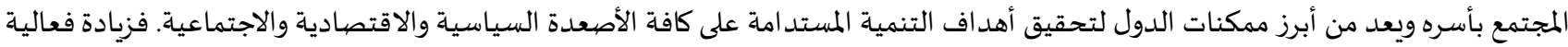
المنظمات التربوية بتطبيق الجوانب المؤصلة إسلامياً من نظرية Z يعد توجهاً تطويرياً يتفق مع تعاليم الدين الإسلامي وقد يحفز مستول مستويات الأداء ويرفع من مستويات الإنتاجية والرضا الوظيفي لدى الأفراد. وهو ما يتفق مع نتائج دراسة العيسى (39:2015) التي أظهرت إدراك التصور الإسلاميلامي للإنسان

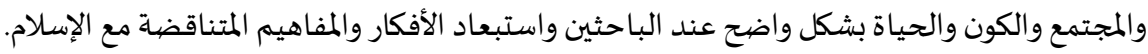
بينما تمثلت جوانب الاختلاف بين بعض خصائص نظرية Z ومقاصيد الشريعة الإسلامية في الوظيفة مدى الحياة، والتقييم والترقية البطيئة،

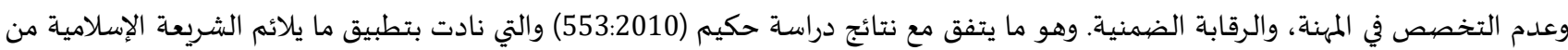

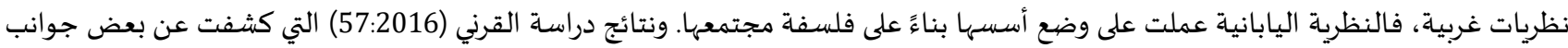

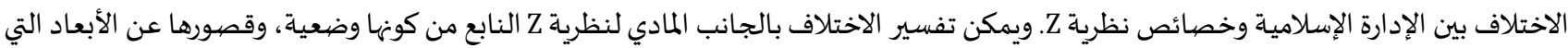

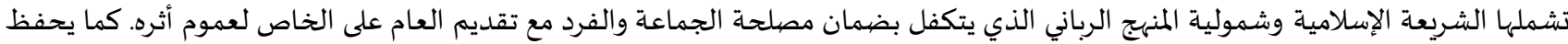

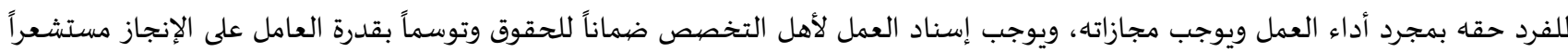

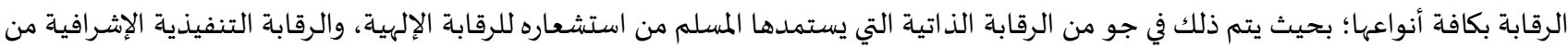

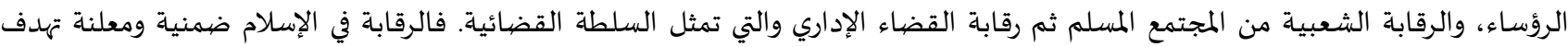

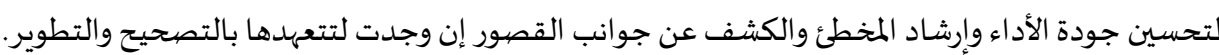

توصيات الدراسـة:

في ضوء النتائج التي تم التوصل إليها توصبي الباحثتان بما يلي:

تطبيق نظرية Z بعد تهذيبها بما يتوافق مع مبادئ وخصائص ومقاصيد الشريعة الإسلامياة.

التعمق في دراسـة أبعاد النظرية وملائمتها مع التوجهات الإسلامية واستنباط جوانب تطبيقية تتسق مع متطلبات الإدارة في العصبر الحاضر. التعمق في دراسة أثر تأصيل نظرية Z وفق مبادئ وخصائص ومقاصد الشريعة الإسلامية عملياً على المنظمات التربوية، وتحديد جوانب إضافية للاستفادة منها في الميدان التعليمي. 


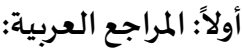

1. إلياس، عبد الوهاب (2013). التفكير الإبداعي من منظور إسلامي، مجلة الشريعة والدراسات الإسلامية: جامعة أفريقيا العالمية، السودان،

.303-256: (21)

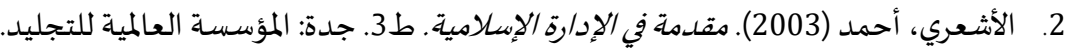

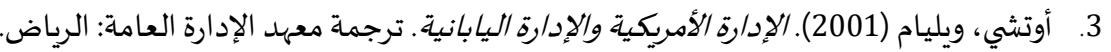
4. بخاري، سلطان (2007). التأصيل الإنلامي لعلم الإدرارة، (د.ن).

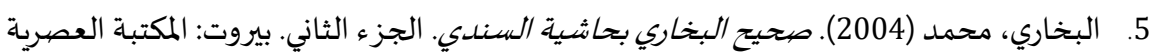

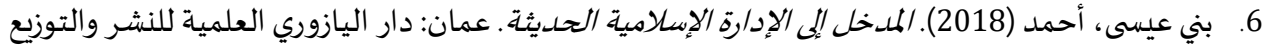
7.

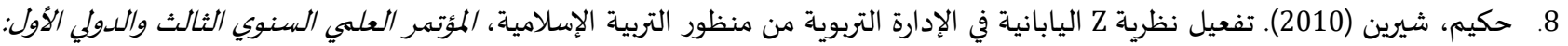

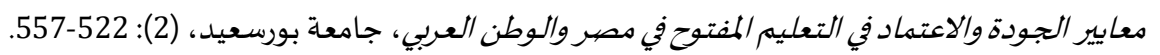

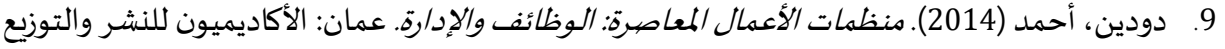

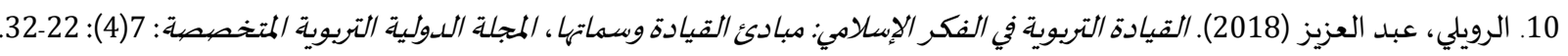

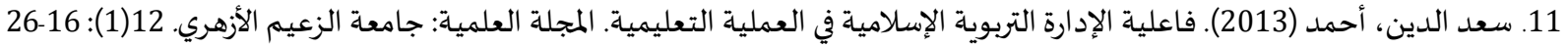
12. سليم، هانم (2019). الطريق إلى التغيير التربوي. دسوق: دار العلم والإيمان

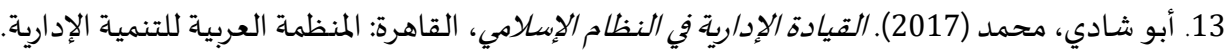
14. شهاب، فادية (2014). التطوير التنظيهي القواعد النظرية والممارسات التطبيقية. عمان: الأكاديميون للنشر والتوزيع. 15. الطبري، محمد (2000). جامع البيان في تأويل القرآن. بيروت: مؤسسة الرسالة الرسالة.

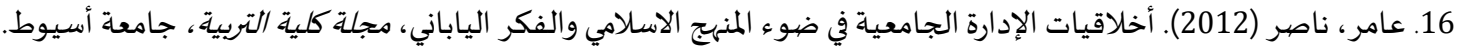

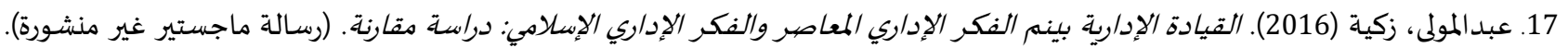
جامعة محمد بوضياف، المسيلة، الجزائر.

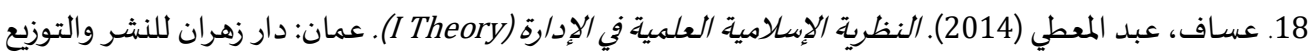
19. العميان، محمد (2001). السلوك التنظيمي في منظمات الأعمال. عمان: دار وائل للنشر والتوزيع 20. العيسي، إبراهيم (2015). واقع بحوث التأصيل والتوجيا الإسلامي للعلوم التربوية في جامعات المملكة العربية السعودية. مجلة العلوم التربوية:

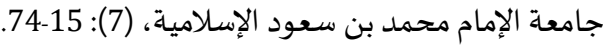

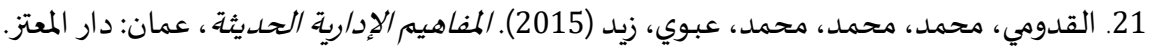

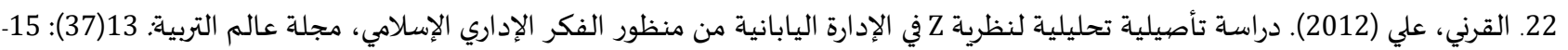

23. القرني، علي (2016). التأصيل الإسلامي لمبادئ وخصائص الإدارة اليابانية وفقاً للمرتكزات العقدية والمصدرية والمقاصدية: دراسة تحليلية من وجهة نظر إسلامية. مجلة عالم التربية: 17(54): 147-205.

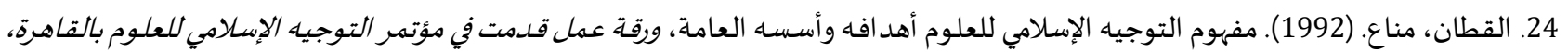
رابطة الجامعات الإسلامية بالاشتراك مع جامعة الأزهر.

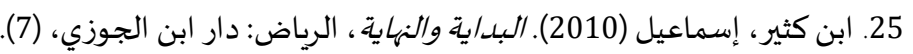
26. المزيد، عثمان (2018). الإدارة اليابانية بمنظور مختلف: مقدمة للمفاهيم الأساسية. تقرير خاص، مركز الملك فيصل للبحوث والدراسات الإسلامية.

27. ملائكة، عبد العزيز (2013). مبادئ ومهارات القيادة والإدارة مع قراءات من المنظور الإسبامي، الدمام: مكتبة المتنبي.

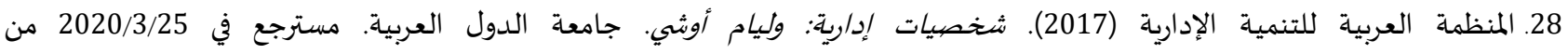
https://www.arado.org/ManagementNews/archives/8258 29. مهورباشاة، عبدالحليم (2017). نقد الأسس الفلسفية للنظريات التويوية الغربية: نحو نظرية تربوية إسالامية. مجلة الفكر الإسلامي المعاصر: إسلامية المعرفة. (87): 106-71) 


$$
\text { 30. أبو نبعة، عبد العزيز (2005). نحو تطوير نظرية عربية في الإد/رة، عمان: مؤسسة الوراق للنشر والتوزيع. }
$$

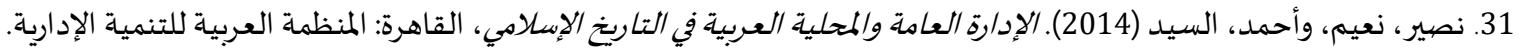

32. يحياوي، نعيمة؛ مقري، زكية؛ عشي، صليحة. (2015). وظائف الإدارة في المنظور الاسلامي. المجلة العالمية للتسويق الإسلامي: الهيئة العالمية

للتسويق الإسلامي. $4(3): 5$

ثانياً: المراجع الأجنبية:

1. Aithal, P. S. \& Kumar, P. M. (2016). Comparative analysis of theory X, theory Y, theory Z, and Theory A for managing people and performance. International Journal of Scientific Research and Modern Education (IJSRME).

2. Lunenburg, F. C. (2011). Organizational culture-performance relationships: Views of excellence and theory Z. In National forum of educational administration and supervision journal. 29(4): 1-10.

3. Ouchi, William G. (1981). Theory Z: How American Business can Meet the Japanese Challenge. New York: Avon Books. 
المجلة الدولية للدراسـات التربوية والنفسية

International Journal of Educational \& Psychological Studies (EPS)

Journal Homepage: https://www.refaad.com/views/EPSR/Home.aspx

www.refaad.com

ISSN: 2520-4149 (Online) 2520-4130 (Print)

\title{
The Islamic and educational rooting of the Japanese (Z) theory
}

\author{
Kholoud Ishaq Bukhari \\ $\mathrm{PhD}$ Researcher in Educational Administration \\ mslavendar333@gmail.com
}

Ashwaq Abdul Rahman Alhaqbani

$\mathrm{PhD}$ Researcher in Educational Administration as0878@gmail.com

\author{
Received : 28/7/2020 Revised : 11/8/2020 Accepted : 2/9/2020 DOI : https://doi.org/10.31559/EPS2021.9.2.17
}

Abstract: The study aimed to identify the background, principles and characteristics of $\mathrm{Z}$ theory in Japanese management, as well as to demonstrate the Islamic rooting for the principles and characteristics of $\mathrm{Z}$ theory in accordance with the basic tenets of contractual, source and functional. The descriptive analytical approach has been used, and the results of the study have shown that The Japanese Z theory was originally developed to reach the reasons for the success of the Japanese organizations, which enhances their strength, and their suitability for application in administrative organizations, as it showed that the majority of the principles of $\mathrm{Z}$ theory correspond to the principles of Islamic law, and that the roots of this theory are found in the Qur'an and Sunnah, and the results also showed that some of Z theory' properties are not included in Islamic legal intentions, and there are no contractual barriers to applying Z theory in Islamic administrative organizations.

Keywords: Theory Z; Japanese administration; Islamic rooting; Islamic administration; educational

\section{References:}

1. ' amr, Nasr (2012). Akhlaqyat Aledarh Aljam'yh Fy Dw' Almnhj Alaslamy Walfkr Alyabany, Mjlt Klyt Altrbyh, Jam't Asywt.

2. 'bdalmwla, Zkyh (2016). Alqyadh Aledaryh Bynm Alfkr Aledary Alm'asr Walfkr Aledary Aleslamy: Drash Mqarnh. (Rsalt Majstyr Ghyr Mnshwrh). Jam't Mhmd Bwdyaf, Almsylh, Aljza'r.

3. Al'myan, Mhmd (2001). Alslwk Altnzymy Fy Mnzmat Ala'mal. 'man: Dar Wa'l Llnshr Waltwzy'.

4. 'saf, 'bd Alm'ty (2014). Alnzryh Aleslamyh Al'Imyh Fy Aledarh (I Theory). 'man: Dar Zhran Llnshr Waltwzy'.

5. Al'ysy, Ebrahym (2015). Waq' Bhwth Altasyl Waltwjyh Aleslamy Ll'Iwm Altrbwyh Fy Jam'at Almmlkh Al'rbyh Als'ewdyh. Mjlt Al'lwm Altrbwyh: Jam't Alemam Mhmd Bn S'wd Aleslamyh, (7): 15-74.

6. Alash'ry, Ahmd (2003). Mqdmh Fy Aledarh Aleslamyh. T3. Jdh: Alm'ssh Al'almyh Lltjlyd.

7. Awtshy, Wylyam (2001). Aledarh Alamrykyh Waledarh Alyabanyh. Trjmt M'hd Aledarh Al'amh: Alryad.

8. Albkhary, Mhmd (2004). Shyh Albkhary Bhashyh Alsndy. Aljz' Althany. Byrwt: Almktbh Al'sryh.

9. Bkhary, Sltan (2007). Altasyl Aleslamy L'Im Aledarh, (D.N).

10. Bny 'ysa, Ahmd (2018). Almdkhl Ela Aledarh Aleslamyh Alhdythh. 'man: Dar Alyazwry Al'Imyh Llnshr Waltwzy'.

11. Bwlwz, Mhmd (2017). Mqasd Alshry'eh Wahdafha Wkyfyh Tf'ylha Fy Almnahj Aldrasyh, Mjlt Aswl Aldyn: (7): 168-246.

12. Dwdyn, Ahmd (2014). Mnzmat Ala'mal Alm'asrh: Alwza'f Waledarh. 'man: Alakadymywn Llnshr Waltwzy'.

13. Elyas, 'bd Alwhab (2013). Altfkyr Alebda'y Mn Mnzwr Eslamy, MjlT Alshry'h Waldrasat Aleslamyh: Jam't Afryqya Al'almyh, Alswdan, (21): 256-303. 
14. Hkym, Shyryn (2010). Tf'yl Nzryt Z Alyabanyh Fy Aledarh Altrbwyh Mn Mnzwr Altrbyh Aleslamyh, Alm'tmr Al'lmy Alsnwy Althalth Waldwly Alawl: M'ayyr Aljwdh Wala'tmad Fy Alt'lym Almftwh Fy Msr Walwtn Al'rby, Jam't Bwrs'eyd, (2): 522-557.

15. Abn Kthyr, Esma'eyl (2010). Albdayh Walnhayh, Alryad: Dar Abn Aljwzy, (7).

16. Mhwrbashh, 'bdalhlym (2017). Nqd Alass Alflsfyh Llnzryat Altrbwyh Alghrbyh: Nhw Nzryt Trbwyh Eslamyh. Mjlt Alfkr Aleslamy Alm'asr: Eslamyh Alm'erfh. (87): 71-106.

17. Mla'kh, 'bd Al'ezyz (2013). Mbad' Wmharat Alqyadh Waledarh M' Qra'at Mn Almnzwr Aleslamy, Aldmam: Mktbt Almtnby.

18. Almnzmh Al'rbyh Lltnmyh Aledaryh (2017). Shkhsyat Edaryh: Wlyam Awshy. Jam't Aldwl Al'rbyh. Mstrj' Fy 25/3/2020 Mn Https://Www.Arado.Org/Managementnews/Archives/8258.

19. Abw Nb'h, 'bd Al'zyz (2005). Nhw Ttwyr Nzryh 'rbyh Fy Aledarh, 'man: M'sst Alwraq Llnshr Waltwzy'.

20. Nsyr, N'ym, Wahmd, Alsyd (2014). Aledarh Al'amh Walmhlyh Al'rbyh Fy Altarykh Aleslamy, Alqahrh: Almnzmh Al'rbyh Lltnmyh Aledaryh.

21. Almzyd, 'thman (2018). Aledarh Alyabanyh Bmnzwr Mkhtlf: Mqdmh Llmfahym Alasasyh. Tqryr Khas, Mrkz Almlk Fysl Llbhwth Waldrasat Aleslamyh.

22. Alqdwmy, Mhmd, Mhmd, Mhmd, 'bwy, Zyd (2015). Almfahym Aledaryh Alhdythh, 'man: Dar Alm'tz.

23. Alqrny, 'ly (2012). Drash Tasylyh Thlylyh Lnzryt Z Fy Aledarh Alyabanyh Mn Mnzwr Alfkr Aledary Aleslamy, Mjlt 'alm Altrbyh: 13(37): 15-72.

24. Alqrny, 'ly (2016). Altasyl Aleslamy Lmbad' Wkhsa's Aledarh Alyabanyh Wfqaan Llmrtkzat Al'qdyh Walmsdryh Walmqasdyh: Drash Thlylyh Mn Wjht Nzr Eslamyh. Mjlt 'alm Altrbyh: 17(54): 147-205.

25. Alqtan, Mna'. (1992). Mfhwm Altwjyh Aleslamy Ll'lwm Ahdafh Wassh Al'amh, Wrqh 'ml Qdmt Fy M'tmr Altwjyh Aleslamy Ll'lwm Balqahrh, Rabth Aljam'at Aleslamyh Balashtrak M' Jam't Alazhr.

26. Alrwyly, 'bd Al'zyz (2018). Alqyadh Altrbwyh Fy Alfkr Aleslamy: Mbad' Alqyadh Wsmatha, Almjlh Aldwlyh Altrbwyh Almtkhssh: 7(4): 22-32.

27. S'd Aldyn, Ahmd (2013). Fa'lyt Aledarh Altrbwyh Aleslamyh Fy Al'mlyh Alt'lymyh. Almjlh Al'lmyh: Jam't Alz'eym Alazhry. 12(1): $16-26$

28. Abw Shady, Mhmd (2017). Alqyadh Aledaryh Fy Alnzam Aleslamy, Alqahrh: Almnzmh Al'rbyh Lltnmyh Aledaryh.

29. Shhab, Fadyh (2014). Alttwyr Altnzymy Alqwa'd Alnzryh Walmmarsat Alttbyqyh. 'man: Alakadymywn Llnshr Waltwzy'.

30. Slym, Hanm (2019). Altryq Ela Altghyyr Altrbwy. Dswq: Dar Al'lm Waleyman

31. Altbry, Mhmd (2000). Jam' Albyan Fy Tawyl Alqran. Byrwt: M'sst Alrsalh.

32. Yhyawy, N'ymh: Mqry, Zkyh: 'shy, Slyhh. (2015). Wza'f Aledarh Fy Almnzwr Alaslamy. Almjlh Al'almyh Lltswyq Aleslamy: Alhy'h Al'almyh Lltswyq Aleslamy. 4(3): 5-12. 